\title{
Horses and Habitations: Iron Age Rock Art from Fortified Hilltop Settlements in the Wadi Draa, Morocco
}

\author{
Youssef Bokbot \\ Institut National des Sciences de l'Archéologie et du Patrimoine (INSAP), Angle Rues 5 et 7, Avenue Allal, El-Fassi, \\ Hay Riad - в Р 6825, Rabat, Morocco \\ bokbotyoussef@yahoo.fr \\ Corisande Fenwick | ORCID: 0000-0002-4645-517X \\ Institute of Archaeology, University College London, 31-34 Gordon Square, London, WC1H oPY, UK \\ c.fenwick@ucl.ac.uk
}

David J. Mattingly | ORCID: 0000-0003-1862-8392

Corresponding author,

School of Archaeology and Ancient History, University of Leicester, University Rd, Leicester, LE1 7 RH, UK

djm7@le.ac.uk

Nichole Sheldrick | ORCID: 0000-0003-0831-586X

School of Archaeology and Ancient History, University of Leicester, University Rd, Leicester, LE1 ${ }_{7}$ RH, UK

ens4@le.ac.uk

Martin Sterry | ORCID: 0000-0002-4863-7735

School of Archaeology and Ancient History, University of Leicester, University Rd, Leicester, LE1 7 RH, UK

martinsterry@googlemail.com

\begin{abstract}
The article presents important results from the Middle Draa Project (MDP) in southern Morocco related to two mid-1st millennium CE hilltop settlements (hillforts) that were associated with significant rock art assemblages. The combination of detailed survey and radiocarbon dating of these remarkable sites provides a unique window on the Saharan world in which the pecked engravings, predominantly of horses, were produced. As the horse imagery featured on the walls of buildings within the settlement, the radiocarbon dating around the mid-1st millennium CE can also be applied in this instance to the rock art. The rarity of rock art of this period within habitation sites is also discussed and it is argued that its occurrence at both these locations indicates that they had some special social or sacred significance for their occupants. While it is commonplace for rock art of this era, featuring horses and camels, to be attributed by modern scholars to mobile pastoralists, a further argument of the paper is that the desert societies were in a period of transformation at this time, with the development of oases. The association of the rock art imagery with sedentary settlements,
\end{abstract}

where grain was certainly being processed and stored, is thus an additional new element of contextual information for the widespread Saharan images of horses and horse and riders.

\section{Keywords}

hillforts - horse imagery - Iron Age - rock art - Wadi Draa Morocco

\section{$1 \quad$ Introduction}

Rock art dating to the North African Iron Age (NAIA, broadly 1000 BCE to $800 \mathrm{CE}$ ) is common in the Sahara (Fig. 1), with a predominant focus on horsemen, horses and - despite their manifest unsuitability for much of the terrain in which the images are found - chariots (Anderson 2016; Camps and Gast 1982; Gauthier and Gauthier 2011, 2015, 2018; Lhote 1982; Muzzolini 1990). Camels and a variety of other, mainly wild, animals (particularly, ostriches, 


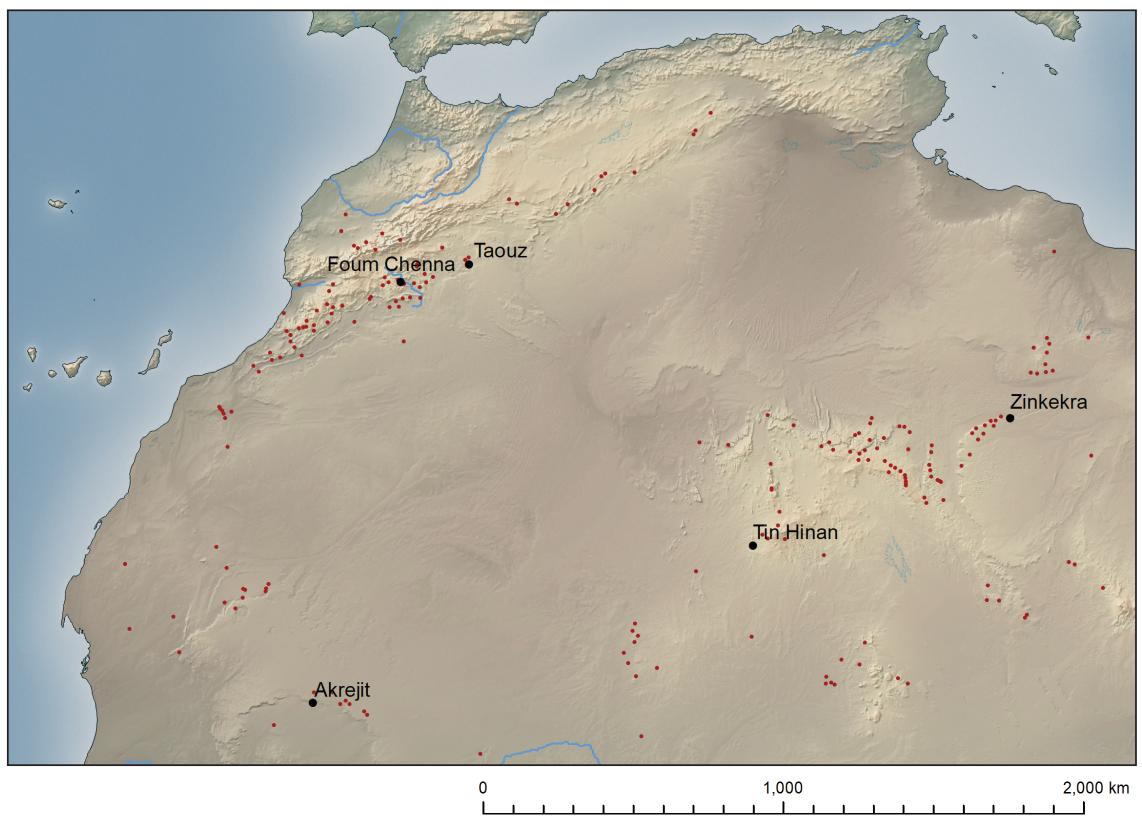

FIGURE 1 Distribution map of 'horse' and 'chariot' imagery in Saharan rock art after Bravin 2020 and Gauthier and Gauthier 2011 (with locations of Zinkekra, Akrejit, Tin Hinan, Taouz, Foum Chenna (Tinzouline, Draa valley) marked)

assorted ungulates, big cats and canids) also appear (Barbaza 2012; Barnett 2019a: 104-06; Bravin 2014, 2020; Gauthier and Gauthier 2011; Lutz and Lutz 1995; Mori 1998). These final phases of Saharan rock art are sometimes referred to as Libyco-Berber, though Bravin (2020: 2) has proposed the alternative 'étage des cavaliers' to reflect the dominance of horse and rider imagery. The vast majority of known caballine (horse) and cameline (camel) art is pecked/engraved or painted on isolated rock faces, boulders or rock shelters in the mountainous areas of the Sahara. Previous interpretations of horse and camel period rock art in the Sahara have tended to assume that it relates primarily to mobile pastoral groups (Simoneau 1972b: 29; Lhote et al. 1989), and in southern Morocco at least, pre-dates the sedentarisation of the oases.

The North African Iron Age (NAIA) is a term that we use to define the autochthonous peoples and cultures of Maghrib and Sahara in the 1st millennium BCE, but also extending in the desert regions beyond the Roman provincial territories until the coming of Islam in the 7 th8th centuries CE. NAIA rock art connected to settlement sites other than rock shelters (for rock shelters, see inter alia, di Lernia and Zampetti 2008) is rare in the Sahara and only a few examples are known (Fig. 1 for locations discussed below). In Libyan Fazzan, the heartlands of the Garamantes, horse imagery is distributed along the Wadi al-Ajal, the escarpment of which is interspersed with settlements. The 1st-millennium вСE Garamantian hillfort site, Zinkekra, has one of the largest concentrations in the wadi with many images on vertical rock faces directly below the summit of the settlement (Barnett 2019b: 227-62; Barnett and Guagnin 2014: 174; Mattingly 2010, 75-77). Small groups of rock art are located within a few hundred metres of six further settlements although the overall correlation between the distribution of images and settlements is weak (Barnett 2019a: 258-64; Barnett and Guagnin 2014: 174-78; Mattingly 2007).

In Algeria, the funerary monument of Tin Hinan (3rd5 th century $\mathrm{CE}$ ), which was most likely originally designed as a fortified dwelling (contra Camps 1974: 509, who nonetheless acknowledged its similarity in plan to a house), had at least three horses and a camel engraved on different parts of its walls (Le Quellec 2008; Pichler and Le Quellec 20o9). In Mauritania, the site of Akrejit (2nd-1st millennium BCE) features two phases of rock art, the first associated with the main occupation of the village, and the second (termed palaeo-berber) after the abandonment of the site; of particular note is an enclosure on the north side that contains the bulk of the horse and camel depictions (Amblard and Vernet 1984). Scenes of riders and equids have also been reported at other sites along the Dhar Tichitt escarpment and are regularly within a few hundred metres of settlements as at Guilemsi and Tarf al-Rjeimat (Campbell et al. 2006; Holl 2002). In Morocco, the walled settlement site of Jebel Afilal lies adjacent to the Wadi Ziz, close to the village of Taouz and a group of large chambered tombs. Capel proposed that it was of pre-Islamic date on the basis of handmade ceramics she 
collected during her survey (2020: 613-15), though the layout looks more similar to Medieval sites in the Draa and it is possible that the settlement here was of two phases, Iron Age and Medieval. The hill has separately been the focus for rock art studies, featuring the largest concentration of engravings of chariots (over 200) at one location anywhere in the Sahara (Gauthier and Gauthier 2015; Rodrigue 2008), and further rock art has been identified in the vicinity of the chambered tombs. A further $15 \mathrm{~km}$ west along the Wadi Ziz, at Hadjart, a small rock art station lies within a few hundred metres of a small walled settlement of possible Iron Age date. The rock art consists of hundreds of signs and schematic drawings including at least one camel and many possible Libyan (old tifinagh) letters over a small cluster of sandstone blocks (Pichler and Rodrigue 2011).

These few examples suggest that rock art images may have been sometimes associated with sedentary habitations. That they are so rare or unremarked in part reflects disciplinary divides between rock art specialists and NAIA archaeologists who rarely work in concert. However, it also stems from the lack of investigation of settlement sites of the 1st millennium BCE and CE in the Sahara and its northern fringes, with only the Libyan Fazzan being more comprehensively investigated by archaeologists (Mattingly 2003, 2007, 2010, 2013; Sterry and Mattingly 2020 for the current state of knowledge). Significantly more research has been done on rock art of this period; however, specialists typically focus on the best-preserved image assemblages that are more often than not in remote locations. Other challenges stem from the tendency of settlements to concentrate in oasis depressions, where continuous intensive exploitation has obscured much evidence for NAIA activity. The good preservation of rock art in the rocky massifs is also helped by the low modern population densities of those areas.

In this article we report on two exceptional discoveries from the Wadi Draa in southern Morocco, where rock art has been found associated with hillfort type settlements alongside evidence of early oasis agriculture (Mattingly et al. 2017 b: $153^{-} 5^{6}$ for the site typology). The sites date between the fourth and seventh centuries CE (TINoo1: 475-643 calCE and TINo15: 345-539 calCE, full details on radiocarbon dates from the survey can be found in Sterry et al. 2020) and the rock art images occur on blocks built into structures within the settlement. Southern Morocco has long been recognised as an important area for rock art studies (Simoneau 1972a, 1977), with some notable sites relating to the later phases of the Neolithic as well as engraved and painted scenes that feature horse (caballine) and camel (cameline) imagery. There are also some significant concentrations of chariot images in Morocco (Gauthier and Gauthier 2015; Rodrigue 2008; Wolff 1982).

\section{$2 \quad$ The Middle Draa Project (MDP)}

The MDP completed an initial exploratory phase of survey work between 2015-2018 (for first reports, see Mattingly et al. 2017b, 2019). The middle section of the Wadi Draa is a perennial river flowing north-west to south-east into the northern Sahara and drawing on water catchments in both the Anti-Atlas and the High Atlas ranges. The valley has been developed as a linear oasis more or less continuously for c.15o km, making it one of the largest and most productive of Saharan oases. Hitherto the NAIA archaeology of the valley had been little explored, with the exception of some pioneering studies of a few rock art sites (see below). The new results from diachronic survey allow us to set the rock art sites in a larger contextual framework and reveal the NAIA period as a time of great change, with increased sedentarisation and the first stages of oasis formation (Mattingly et al. 2018, 2019; Sterry et al. 2020).

An important initial stage of our research was the identification and mapping from satellite imagery of ancient settlements and pre-Islamic funerary monuments along the flanks of the valley, with many locations then visited by our survey teams. The wadi was divided into numerous subzones, designated by three-letter codes and sites located were numbered in separate sequences within each sector. The focus of this article is the Tinzouline area (subzones TIN and TAG) between Agdz and Zagora in the northern part of the Middle Draa (Fig. 2). Survey work by the MDP in the Tinzouline area focused on two wadis - Foum Chenna and Assif Wiggane - lying a few kilometres to the south-west of the main Wadi Draa in this sector. After an initial visit undertaken in January 2015, follow-up survey and test-pitting at two sites was conducted in November 2015 with an additional campaign in November 2016 on the two main identified NAIA sites (TINoo1 and TINo15), involving further test-pitting, photography, DGPS recording and drone survey.

Archaeologically, the region of Tinzouline is best known for four groups of rock art and Libyan (tifinagh) inscriptions:

1) Foum Chenna (TINo12 - 30.4846 $6^{\circ}$. $6.1696^{\circ} \mathrm{W}$, detailed in numerous publications - Abioui et al. 2018; Glory et al. 1955; Pichler 2000a, 200ob; Reine 1969; Rodrigue 1989; Searight 2001; Simoneau 1972b);

2) Assif Wiggane (TINo15 and TINo27 - 30.4562 ${ }^{\circ}$ N 6.1045 W, Pichler 200oa, 20oob; Pichler and Rodrigue 2003; Simoneau 1972b); 


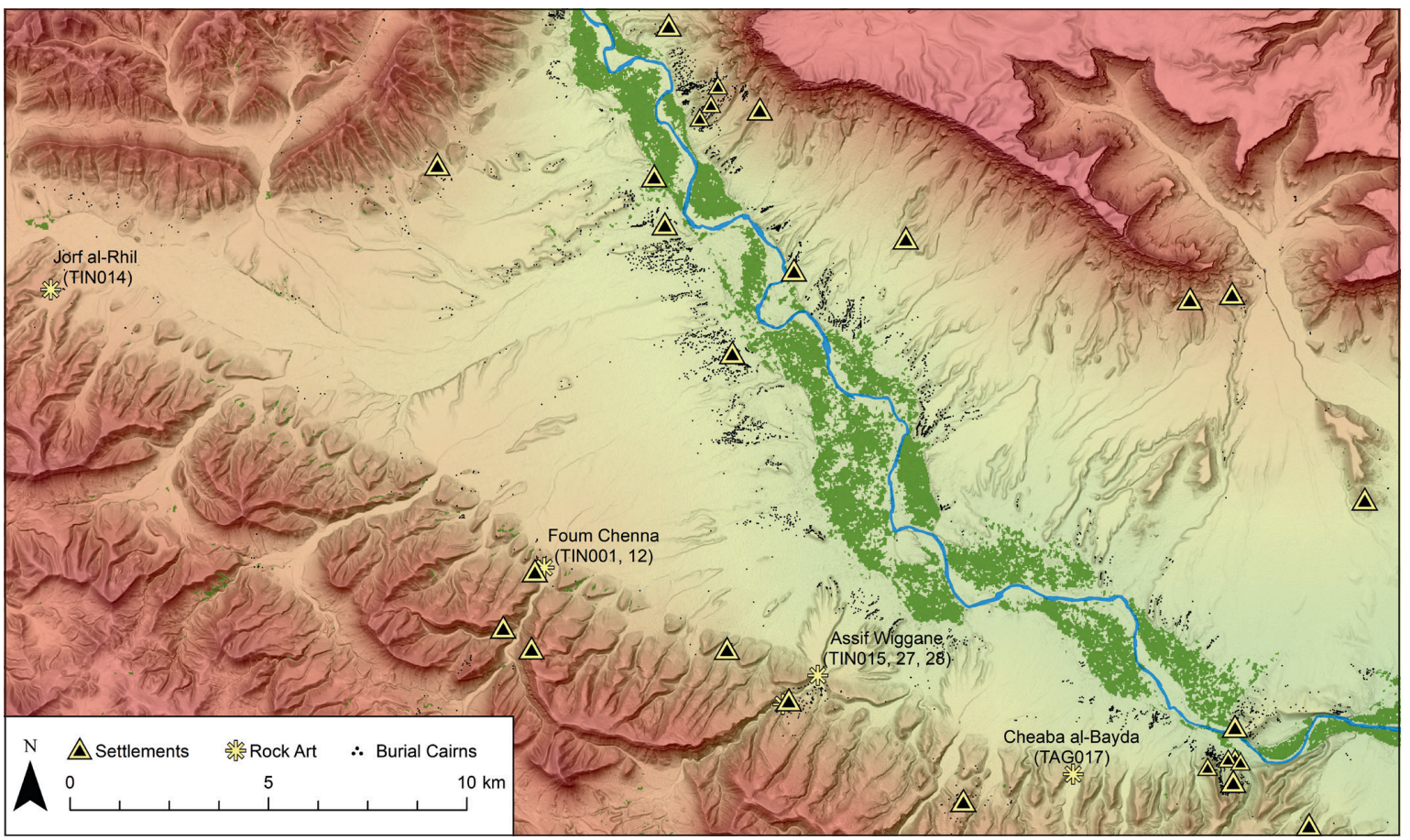

FIGURE 2 Map of Tinzouline area, showing the four designated areas of rock art sites and NAIA settlements and burial cairns

3) Jorf al-Rhil close to the mouth of the Wadi al-Féhi (TINo14 $-30.5445^{\circ} \mathrm{N} 6.3011^{\circ} \mathrm{W}$, also called Khil or Tasminerth, Glory et al. 1955; Reine 1969; Ruhlman 1939);

4) Cheaba al-Bayda (Elbeida) at the mouth of al-Batha al-Bayda (TAGo17 - approx. $30.4415^{\circ} \mathrm{N} 6.0287^{\circ} \mathrm{W}$, also called Rich M'Bidia, Pichler 2oooa; Searight 2001; Simoneau 1972b).

Simoneau (1972b, 27) also mentions a fifth location (not on Fig. 2) close to Rebat al-Hajer, $\left(30.4073^{\circ} \mathrm{N} 5.8708^{\circ} \mathrm{W}\right)$, but this cannot be verified at this time. All these assemblages of rock engravings consist primarily of figures on horseback with horses, camels, ostriches, wild ungulates, big cats, canids and others along with Libyan inscriptions and more recent additions up to the present day (e.g. cars). The link between the equine imagery and the Libyan inscriptions is an important chronological indicator and supports an NAIA or later date (Pichler 1999, 2000a, 200ob, 2007; Pichler and Rodrigue 2001). Despite a number of publications, the rock art corpus has never been systematically catalogued or published in full, nor has there been much investigation of the relationship between the first two groups and two adjacent NAIA settlement sites (TINoor and TINo15), where as we shall demonstrate, many rock art panels are also found. Before turning to the two hillfort sites, a general description of what is known about each of the four rock art clusters provides useful context.

\section{$2.1 \quad$ Foum Chenna (TINo12)}

Foum Chenna is the most famous of the sites in the Tinzouline area, with a dense concentration of pecked imagery on steep rock faces (Fig. 3). The site has been the focus of numerous articles over the years as well as two PhD theses (Searight 2001; Bravin 2014). The site was first published by Glory et al. (1955) with more detailed descriptions added by Reine (1969: 37-42) who estimated that there were around 3,00o figures distributed across a few hundred panels. Reine (1969: 39) noted the overlooking NAIA hillfort site of TINoo1, which he thought to be contemporary along with the medieval settlement of TINoO2 (c. $2 \mathrm{~km}$ to the south-west), but described these as 'des azib fortifiés; des retranchements de nomades et de pasteurs armés'.

He divided the rock art figures into four degrees of patination, each with different styles and iconography, but these are difficult to substantiate on the ground. Searight (2001:120-130) was the first to systematically survey a portion of the rock art at the base of the wadi (TINo12), cataloguing 216 panels with 425 figures. Included within this was a group of 51 loose blocks on the valley bottom, many of which were damaged or destroyed by floods between 1992 and 1997 and others of which were used in the construction of animal enclosures on the side of the wadi. Bravin $(2014,2020)$ also studied the site identifying 2,555 figures, of which 434 were horse and riders, the majority of whom were armed with a round shield, and 16 with a 


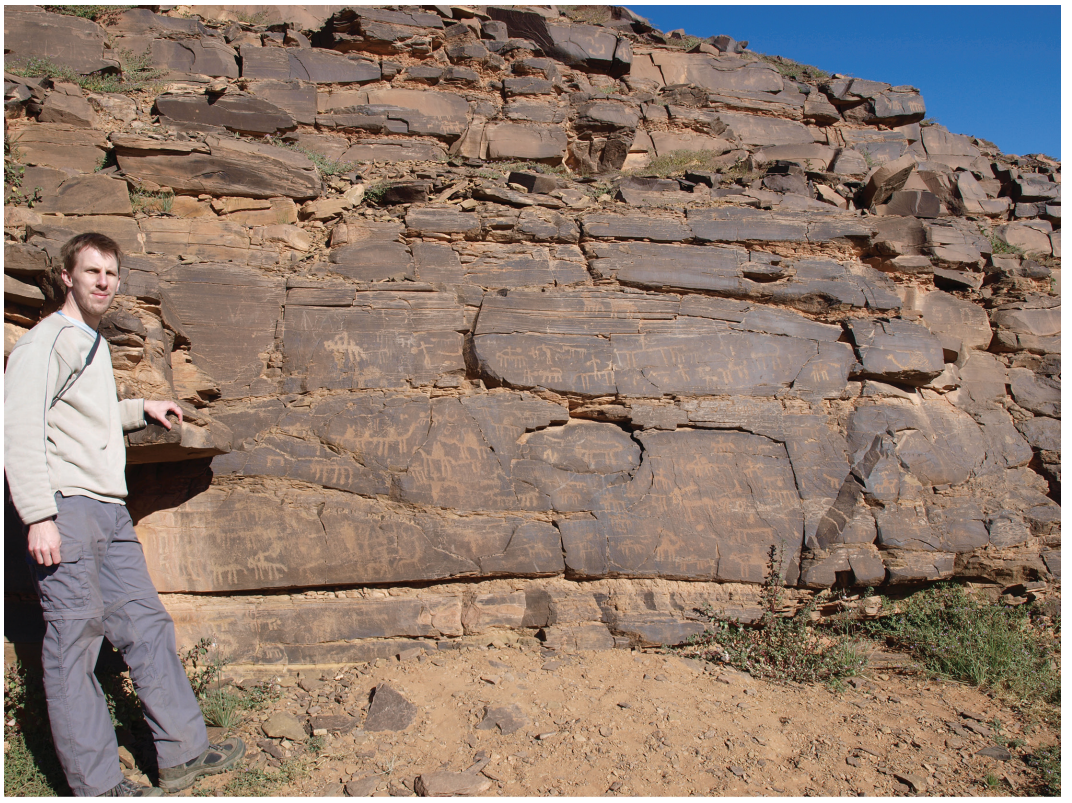

a

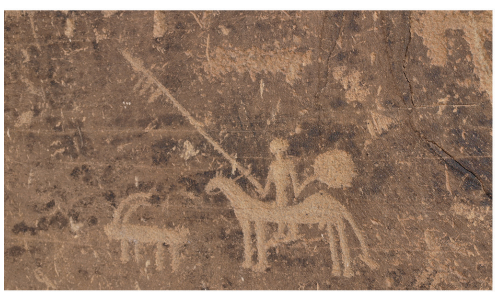

b

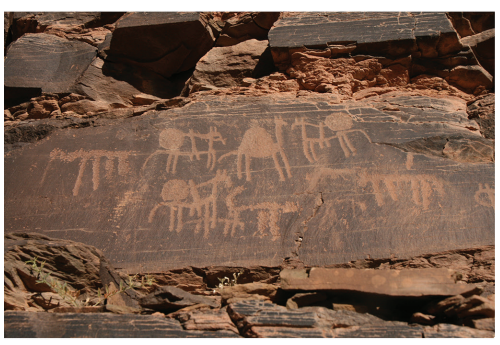

d

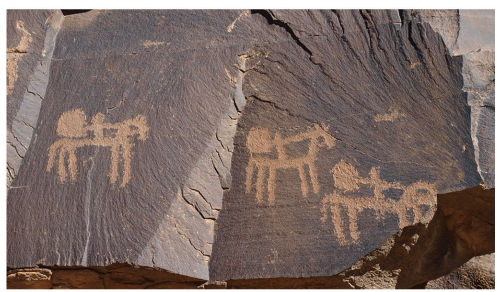

C

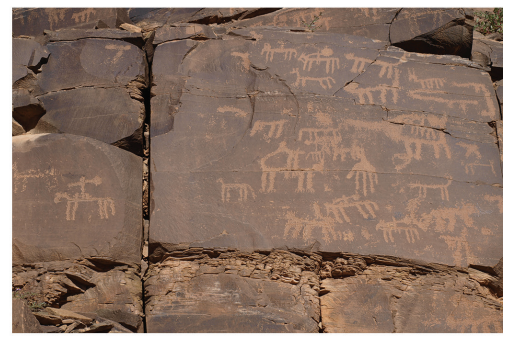

e
FIGURE 3

Some characteristic examples of rock art at TINo12 (Foum Chenna): a) General view of part of rock face; b) Horseman with lance and shield approaching a Barbary sheep or other wild ungulate; c) three simple horsemen with circular shields; d) three horsemen with circular shields surround a camel, with three other quadrupeds of less clear identification (perhaps dogs to left and right and a large feline centre bottom; e) complex palimpsest scene featuring numerous horses with riders, perhaps some unridden horses, dogs, wild felines ungulates, ostrich lance. Alongside the horse imagery she also noted 73 camels and 88 Libyan inscriptions, as well as a range of hunted animals (ostrich, Barbary sheep, antelope, oryx, big cats). An additional catalogue of the Libyan inscriptions was undertaken by Pichler (200oa) who recorded 30 panels and c.6o lines of script, some of which incorporate figures of animals in and around the letters.

\subsection{Assif Wiggane (TINo15 and TINo27)}

The sites of Assif Wiggane were first discovered by Simoneau who visited in 1967 (1972b: 27-31) and drew attention to the hillfort (TINo15) where most of the rock art corpus is located, though the description of the hillfort as 100 ha in area and the sketch view are significantly erroneous (however, there is no doubt that it is our site TINo15, as the photograph of one of the main scenes - though printed back to front - can be identified with an extant panel). He noted the presence of numerous sandstone blocks across the site that sometimes had more than ten horses in each scene, the regularity with which riders had shields and occasionally lances, and a small number of other figures: scorpions, cupules and geometric designs. As with Foum Chenna, many scenes were also identified on the north bank of the wadi (TINo27) between the hillfort and the mouth of the wadi including several Libyan inscriptions and a scene of an ostrich hunt that is very similar to one at TINo12. Simoneau also mentions in passing that there are scenes at the base of a ruined town, but it is unclear if he was referring to the NAIA hillfort (TINo15) or the Medieval settlement located c. $2 \mathrm{~km}$ upstream to the south-west (TINoo5/TINo33). Simoneau also suggested that the location of the imagery and settlement were 
related to access to the copper mines at Bleida (1972b: 29). As with Reine's interpretation of Foum Chenna, for Simoneau the life of the creators of the rock art was dominated by the activities of nomads: war and the breeding and hunting of animals (1972b: 29). There has been little new research subsequently beyond the identification of two lines of Libyan by Pichler and Rodrigue (2003: 24).

\subsection{Jorf al-Rhil (TINo14)}

The site of Jorf al Rhil (literally, 'the horse cliff') is the most northerly of the Tinzouline group of rock art and is located in the mouth of a tributary of the Wadi Tasiminerhf. Unlike the other sites described, it is not on a route through the Jebel. The site was first noted by Ruhlmann (1939) and is detailed by Reine (1969: 43-47). There are at least six panels on bedrock and boulders on the north-west side of the wadi. There is a small scatter of cairns around $750 \mathrm{~m}$ to the north-east and the enclosures and buildings of a fairly recent pastoral encampment in the immediate vicinity of the site, but there is no direct association with an archaeological site. The imagery consists mainly of groups of 'horse and rider' imagery as well as some depictions interpreted as fibulae and bracelets, which Reine considered to be more recent in date (1969: 44). A rather unusual depiction is a scene of c.4O sub-rectangular shapes that are thought to be hoofprints (since Simoneau's visit, erosion around the base of the rock has uncovered a quadruped). A similar scene has been found in the Ktawa region, in the Jebel east of Ksar al-Kabir, some $100 \mathrm{~km}$ to the south-east (Reine 1969: 47).

\subsection{Cheaba Albayda (Elbeida) (TAGo17)}

Cheaba Albayda is the most south-easterly of the Tinzouline group of rock art. Simoneau (1972b: 27) visited in 1968 and recorded that there were four small stations in different valleys, but did not provide a description except to note that there was no major site. The stations have been mentioned in passing by other authors without adding further details, although they can be assumed to be of similar iconography as the other stations in the Jebel. Of note in this area is a large NAIA hillfort (TINo17) that has been identified from satellite imagery and which lies on a peak between the mouths of two wadis.

In addition to these sites in the Tinzouline area, there have also been some recent discoveries of multi-phase rock art (both engraved and painted) from a series of rock shelters in the Jebel Bani area (Ifran-n-Taska) and close to the pass of Foum Laachar just west of the southern part of the Middle Draa (Moumane et al. 2019; Skounti et al. 2012; Zampetti et al. 2013). These rock art stations include images of horses, mounted and unmounted warriors with round shield and lance, bi-triangular human figures (very similar to material from Libyan Fazzan, Barnett 2019a: 104-05, 131; di Lernia and Zampetti 2008) and Libyan inscriptions. These discoveries suggest that rock art of the horse and camel phases could have been much more widespread, but that the poor survival of painted scenes has hitherto limited their identification.

\section{3}

The Two NAIA Hillforts with Associated Rock Art

TINoor lies at the point where the tributary wadi emerged from the range of hills at a distance of c. $7 \mathrm{~km}$ south-west from the main channel of the Wadi Draa (Fig. $4 a-b)$. It is directly adjacent to the celebrated Foum Chenna rock art site (TINo12) described above, which also marks this key transitional point in the landscape. TINo15 on the other hand is set back c. $1.5 \mathrm{~km}$ from the point of egress of Assif Wiggane from the hill range into the plain to south-west of Tinzouline (Fig. $5^{\mathrm{a}-\mathrm{b}}$ ). The site sits on a semi-isolated rocky plateau in a bend in the wadi, with good views towards the wadi entrance and the Draa beyond (Fig. 6). There are several stations of engraved rock art along the sides of Assif Wiggane, but these are much less concentrated than at Foum Chenna (TINo12). From the mouth of Assif Wiggane the first group encountered is on the north-west side of the wadi at the point where the valley narrows just before the breakthrough into the Tinzouline plain (TINo27). There are multiple panels over a distance of several hundred metres with figures including horses and a camel and unidentifiable quadrupeds (the figures are especially schematic) and at least one Libyan inscription. Additionally, there are many Arabic inscriptions (including verses from the Quran) that in some places deliberately obscure underlying imagery and are likely fairly recent. After the wadi turns round the front of the hill of TINo15 there is another group of rock art stations, mostly on the south-east side of the wadi over a distance of 300-400 m. These include several horses and riders which are stylistically similar to the imagery found on the plateau of TINo15 and a few camels, but no extensive or complex scenes were observed. As with TINoo1, the rock art stations do not appear to extend more than c. $2 \mathrm{~km}$ from the narrow point where the wadi breaks through the hill front, however, there is an extensive Medieval settlement (TINoo4/TINo33) located c.1 km further south-west from the last station and an early modern granary a further $2 \mathrm{~km}$ along. 

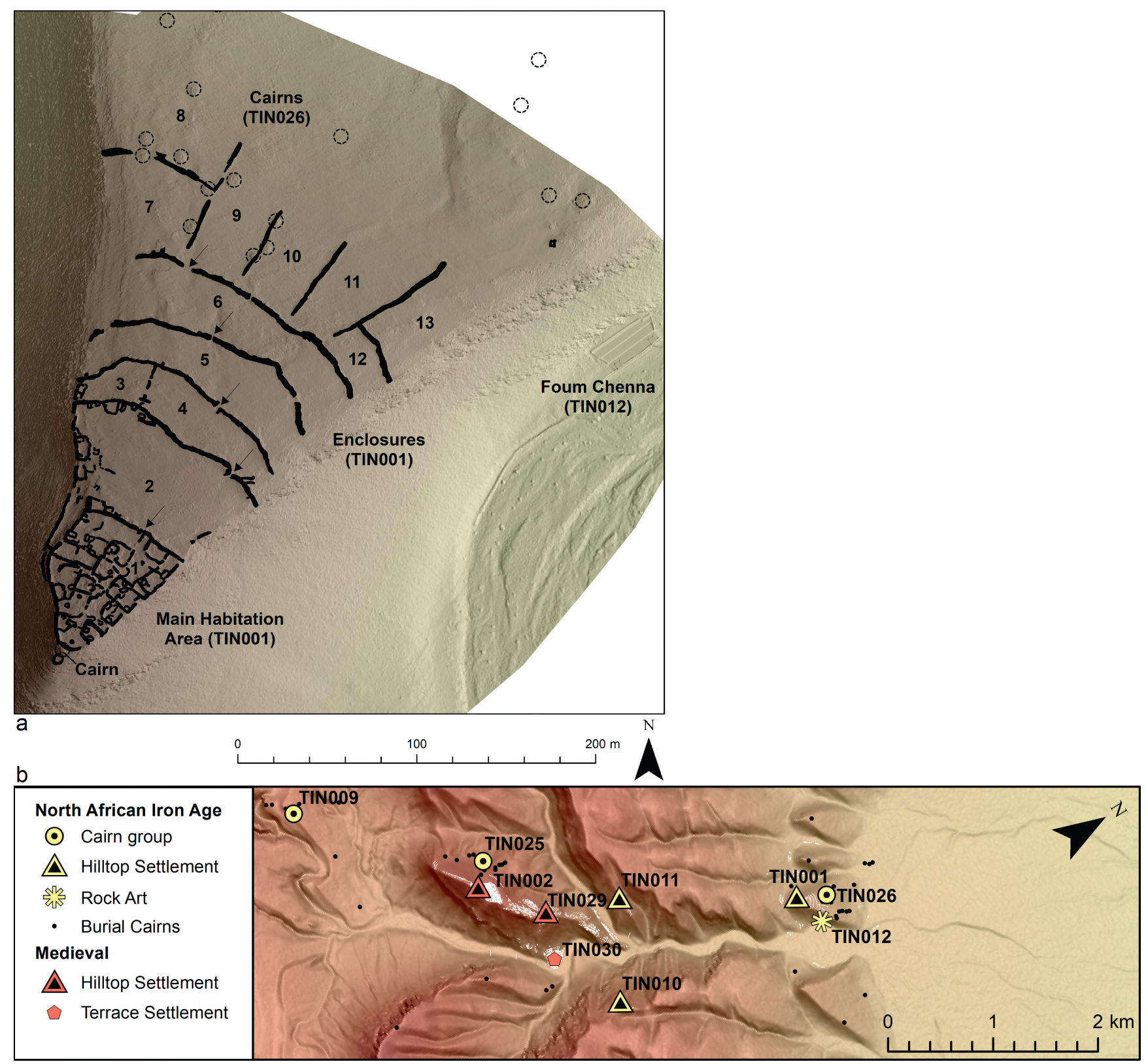

FIGURE 4 TINoo1: a) Numbered structural plan of the hillfort TINoor in relation to Foum Chenna rock art site TINo12, derived from drone survey; b) map of Foum Chenna area, showing location of TINoo1/o12

\subsection{TINoor: General Description}

The settlement site of TINoor is a small and roughly triangular walled hillfort (Fig. 4a), perched at the top of a hill facing the Wadi Draa, at the mouth of Foum Chenna and immediately above and to the west of the rock art site (TINo12). The site is protected by cliffs and very steep escarpments to the west, east and south, but can be approached more feasibly from the north up a steady slope. A series of walls with gates cut across the slope in this direction providing outer defences for the site as well as enclosures for animals to be corralled within.
At the northern extent of the site there are four perpendicular walls running downslope from the outer enclosure wall, creating five enclosures that were left open to the north, of which the outer (eastern and western) ones were further subdivided by a short cross-wall (Fig. 4a, numbers 7-13). In total this accounts for 12 enclosed areas in addition to the main habitation area (1), with a total area of 3.5 ha. The walls of the western enclosures (7-9) impinge on nine cairns (TINo26) which form part of a larger distribution of cairns down the slope of the hill. Several of these cairns were either incorporated into or overlaid a wall line, but the sequence is not clear cut. 

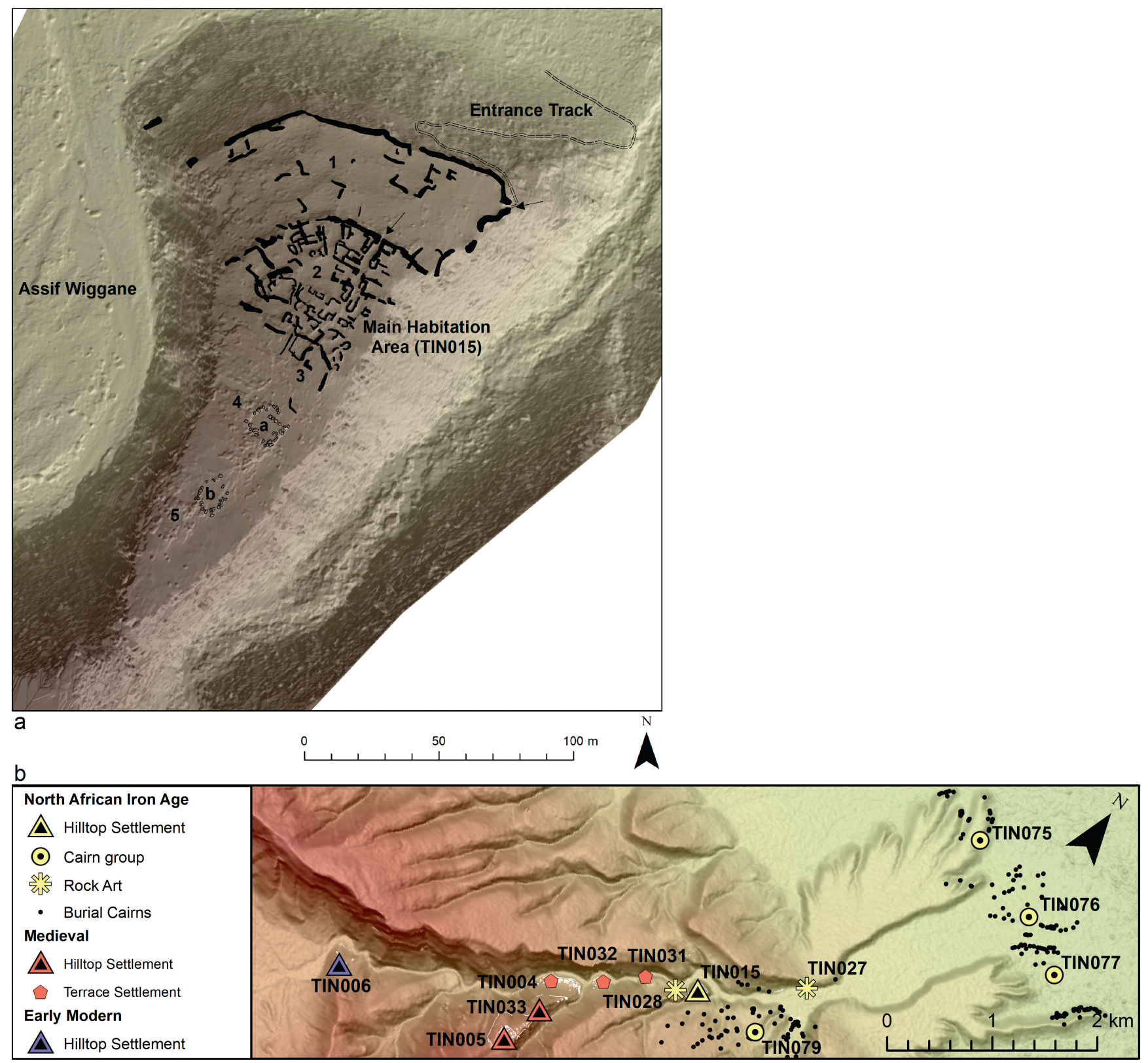

FIGURE 5 TINo15: a) Numbered structural plan of the hillfort TINo15, derived from drone survey; b) map of Assif Wiggane area, showing the location of TINo15

Above this first group of open enclosures, there is a series of three low drystone walls cutting across the hill from east to west and creating a series of large enclosures, each entered through a well-built gate, which was offset from the one below (3-6). Apart from a couple of slight structures in enclosure 3 and a possible north-south division towards the west, there are no signs of additional structures in the outermost enclosures. To the south again, enclosure 2 (c. 0.57 ha) was mostly clear of structures or large boulders. The entrance to this enclosure was through a gateway in the wall in the north-east corner. On the west side of the enclosure are a number of small enclosures and structures, two of them potentially for habitation.

The core settlement area comprises a walled enclosure (1) of c. 0.36 ha at the summit of the hill, within which are c. 21 small enclosures on either side of a central alleyway that leads to the highest point of the hill, where there is a prominent cairn or possible funerary monument. Around half of the enclosures have one or two small sub-circular structures built against the enclosure walls, most likely small huts; the enclosures themselves appear too large to have been fully roofed. 


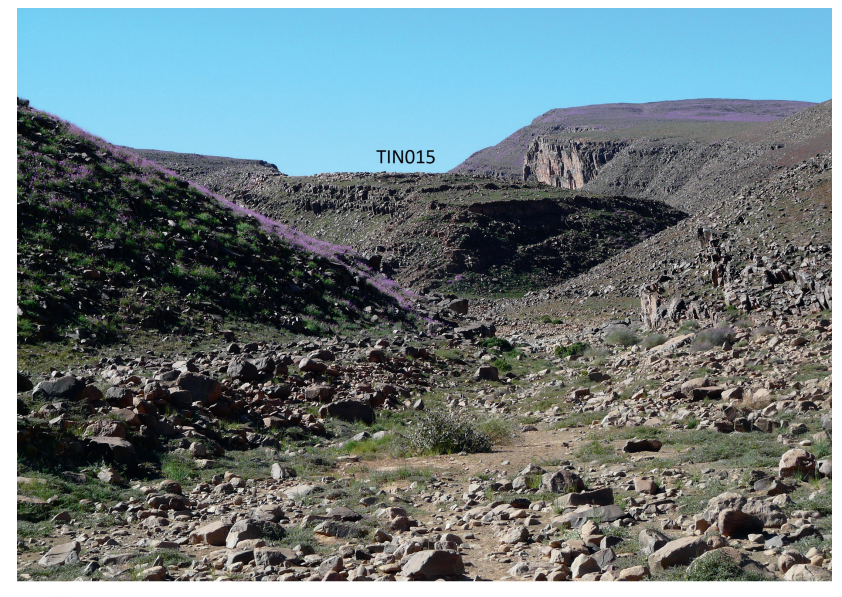

a

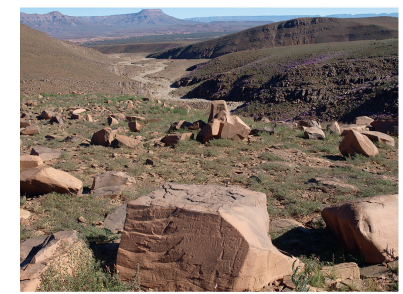

b

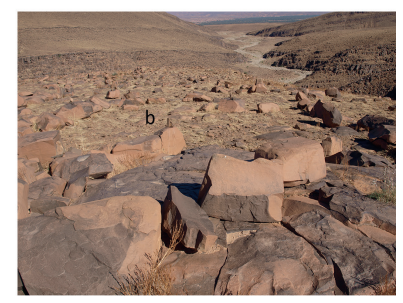

C

FIGURE 6 Landscape setting of TINo15: a) General view of site from the wadi below, showing its position on the bend (the defences and habitation structures are visible in upper centre of image); b) view from upper plateau area (zones 4-5) out towards mouth of Assif Wiggane, with oasis of the Draa in distance (note horse engravings on boulder in foreground); c) cleared area and rough oval enclosure $b$ adjacent to tabular bedrock area

This main habitation area of the site is generally wellpreserved. Slab-built walls stand up to c. $1.8 \mathrm{~m}$ tall in places, but more commonly c. $1 \mathrm{~m}$, with doorways generally visible. The masonry suggests two phases of construction, the first of loosely-coursed blocks and boulders and the second of rough coursed drystone slabs, although the presence of the latter makes it sometimes difficult to trace the former. The early phase was probably defined by large block enclosures, some decorated with rock art of horses or warriors on horseback. Some of the enclosures appear to have been subsequently reused, with several buildings built up further in coursed drystone slab walls and some enclosures being entirely filled to a depth of c. 0.5 $\mathrm{m}$ with flattish slabs. These 'filled' enclosures had traces of circular, corbelled pit structures within them, which following a test excavation and comparison with examples at TISoo7 appear most likely to be collapsed storage silos. The infilling of these enclosures would have made them unsuitable for habitation and is therefore indicative of a later phase of use. Finds recovered from a survey of the site included handmade ceramics, many of which were from NAIA type cordon decorated jars, and fragments of three rotary quernstones.

\subsection{TINo15: General Description}

The hillfort sits on a low, but precipitous, rocky promontory located on the southern side of a prominent bend in the Assif Wiggane (Fig. 5b). At the most northern extent of the site, below the hillfort, directly adjacent to and just above the level of the wadi, there are a small number of enclosures and buildings in a poor state of preservation of unknown date (while they could be contemporary with the site they appear to have been reused in the recent past by pastoralists). Access to the hillfort was via a well-engineered path which zig-zags up from the level of the wadi on this north side (Fig. 5a). Although eroded in places, where best preserved it was c. $2 \mathrm{~m}$ wide and suitable for horses or other pack animals to pass each other. The northern edge of the plateau was protected by a substantial outer wall accentuating the natural cliff. The wall continued for a distance down the east side of the site, but the height of the cliffs provided adequate natural defence for the southern part of the plateau site. A well-built gateway in the north-east corner of the main north wall was the only access point and those approaching the site had to pass directly below the defensive wall for some distance before reaching it. About $20 \mathrm{~m}$ down the entrance track below the gate there is a prominent engraved rock art panel on the sandstone cliffs showing two well-executed warriors with lances on horseback and a large feline (Fig. 7). There are further engravings of horses on a number of blocks built into the gate and wall and on visible bedrock around the entrance.

Like TINoo1, the plateau here was slightly tilted with the ground rising to the south. In shape it is roughly triangular, narrowing like an inverted flat-iron to a point at the south (Figs $5 \mathrm{a}$ and 6a). The interior of the site can be divided into five areas from north to south - an outer northern enclosure (1), a main habitation zone (2), a southern group of enclosures (3), a northern bedrock area (4) and a southern bedrock area (5). The total area of the plateau is 1.11 ha (cf. the fanciful 100 ha of Simoneau 1972b: 29).

Through the gate, one enters a lower enclosure ( $0.43 \mathrm{ha}$ ) demarcated by the main northern defensive wall and a roughly parallel major terrace wall set back 30-40 $\mathrm{m}$ from it. Although this area contains traces of terrace walls and small enclosures, it does not appear to have been densely occupied, at least in the final stages of the site. There are frequent rock carvings of horses on stones used in delimiting the enclosures and structures. 


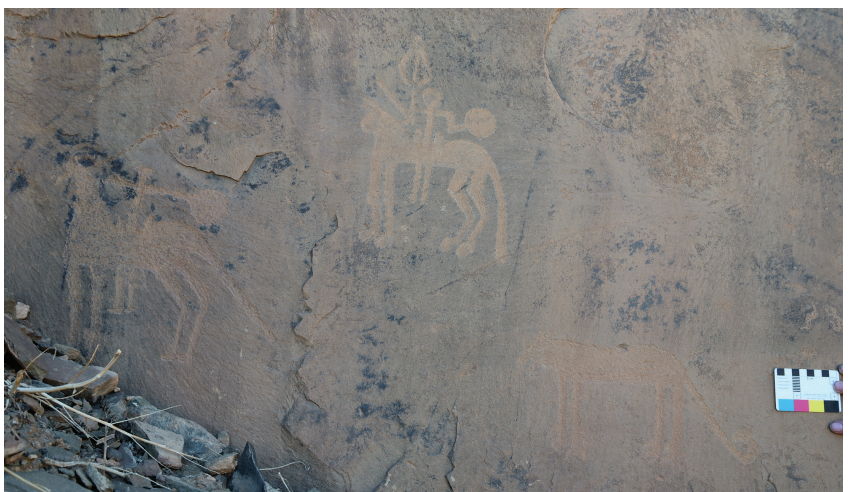

a

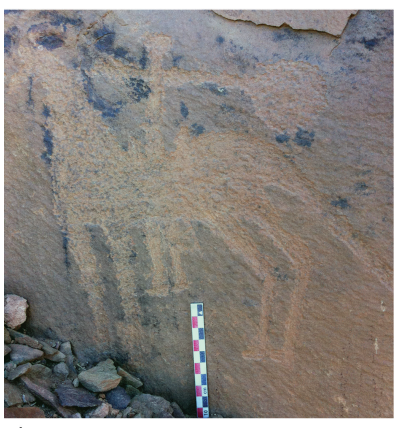

$\mathrm{b}$

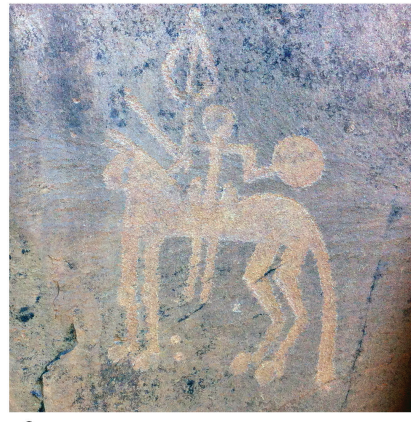

c

d

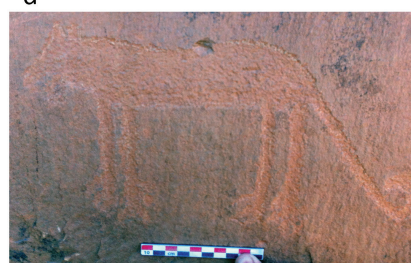

FIGURE 7 TINo15 RA panel 510 (on approach to gate of site): a) the entire scene showing two armed horse riders and a large feline (visible just to left of the scale); b) detail of lower left horse and rider; c) detail of upper horse and rider with small shield and exaggerated lance head, reins and saddle and more realistic representation of horse's physical features; d) the large feline recognisable by shape of muzzle, pricked ears and slight upcurl of tail

The main habitation area in the centre of the site ( 0.25 ha) was delimited on its north side by a thick wall, terraced into the plateau and with a well-constructed gate facing the main entrance to the hillfort. The habitation is divided into two sectors by a second east-west terrace wall. The northern part of the habitation area was divided into nine or 10 enclosures, positioned on either side of a central lane, each containing one or more circular or oval buildings. As at TINoo1, there were frequent engravings of horses on the smaller blocks utilised for building construction and a concentration of such imagery follows the central lane through this part of the site (Fig. 8a-b). The presence of six fragments of rotary quern stones suggests crop processing and this is confirmed by identification of cereal grains (barley and wheat) from the trial trenching, providing material for AMS dating (full details of six AMS dates are given in Sterry et al. 2020: 246). Dupuy (2017) reminds us of the cereal consumption needs of horses in the Sahara - another factor that links their spread to oasis creation. Other finds include a possible ceramic spindle whorl and an assemblage of typical NAIA handmade ceramics with many cordon decorated jars (Mattingly et al. 2017 b: 166, fig. 20).

The southern end of the main settlement zone comprised a group of buildings behind another substantial terrace wall that separated it from the northern set of structures. Its southern limit was marked by another terrace wall that effectively separated it from an open area beyond to the south. The total area of the hillfort from the main front rampart to the rear of the third zone of structures is 0.73 ha.

The open southern part of the site measures 0.38 ha and encompasses the highest point on the rocky promontory. This area was kept free of enclosures and buildings, providing wide views over the wadi below (Fig. 6b-c). In two areas a tabular bedrock formation stands proud of the general ground level and there are many large natural boulders separated from this that are strewn across the plateau, in two places seemingly arranged in rough ovals (marked as a and b on Fig. 5b). There is abundant rock art on the boulders, the upraised tabular bedrock formation and the lower bedrock surfaces (Figs 6b-c; 14), though the imagery is most heavily concentrated on the first two of these rather than randomly/evenly spread across all parts of the plateau (see below).

The Rock Art Assemblages

In rock art studies, terms like 'panel', 'composition', 'scene' and 'image' need to be carefully deployed (Lensssen-Erz 1992). In our study the rock art imagery at both sites was systematically recorded with each panel (a stone block, the face of a boulder or area of a rock surface) given a number, photographed and interpreted on site as to content, with its precise location determined by DGPS survey. A panel most commonly comprised a single figure on an isolated stone, but there were also more complex scenes of multiple images/figures on a rock face. Careful examination of the photographs subsequent to the field recording has enabled further revisions and refinements of interpretation. Across the two sites 573 panels were recorded, involving 1,601 individual human or animal components. A drone survey was conducted to generate data for a $3 \mathrm{D}$ model, Digital Surface Model (DSM) and orthophotograph of both sites. This allows us to look at the context 


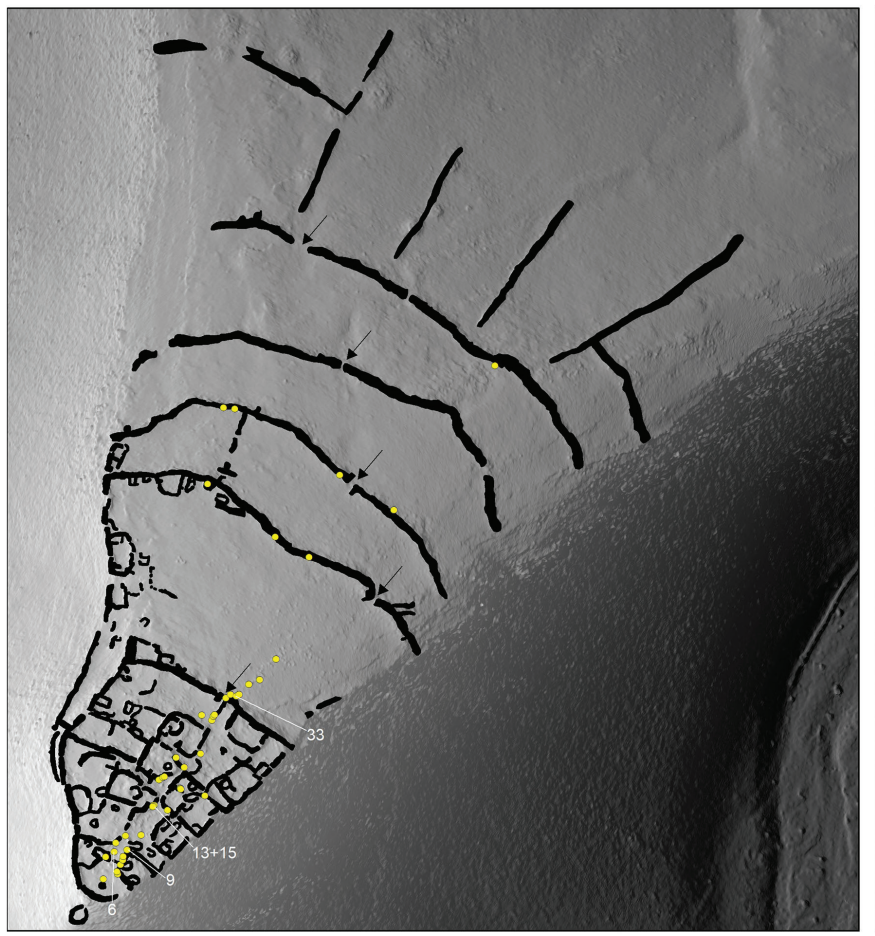

a 0
75

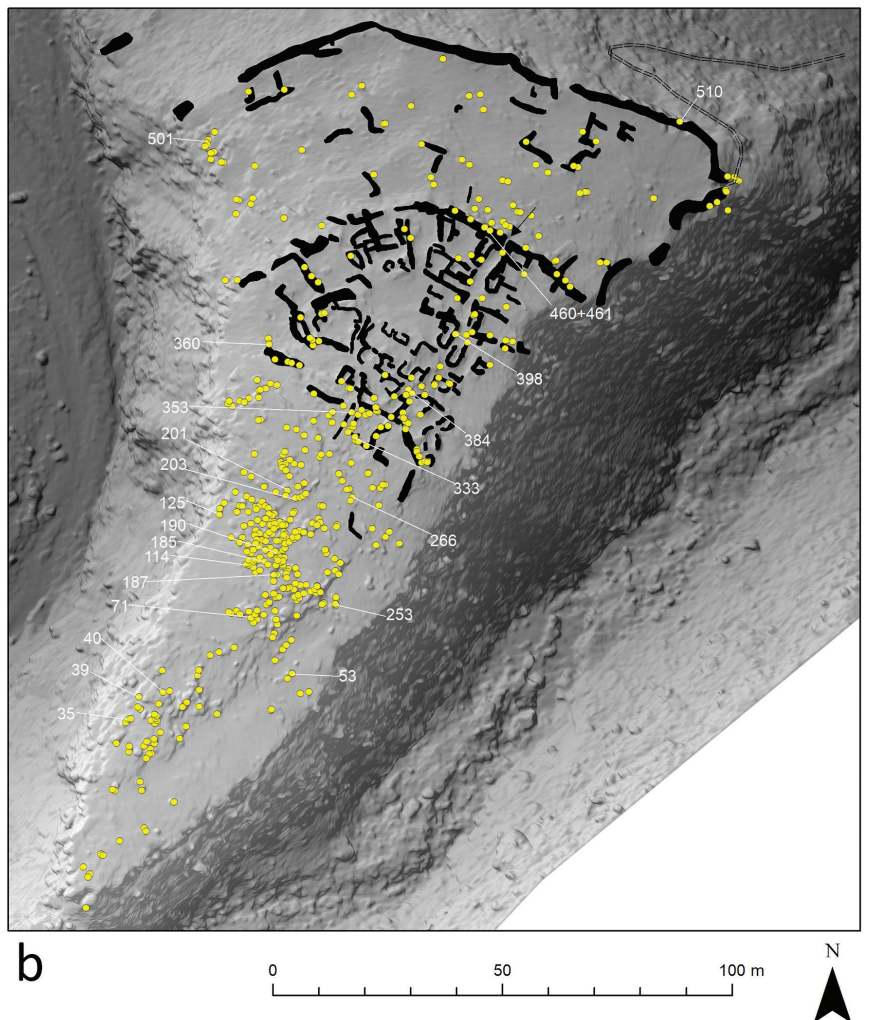

FIGURE 8 Plans of a) TINoo1 and b) TINo15 showing locations of all rock art and related engravings. Numbers relate to main panels (RA numbers) referred to in the text

of each individual panel in relation to archaeological and natural features on each site (Fig. 8a-b). While further work is planned at these sites in the second phase of the project, the information already gathered is sufficiently important and unusual to merit independent presentation here, in particular because of the direct association of engraved imagery with two settlement sites, which have been radiocarbon dated to $475^{-643}$ calCE (TINool) and 345-539 calCE (TINo15).

On both sites, the images were almost entirely pecked and correspond closely with what has been defined as the 'Libyco-Berber' style (Barbaza 2012; Bravin 2014, 2020; Searight 2001), generally considered to date to the early centuries CE. Although the scenes can be a metre or more across, most of the individual elements are small figures of horses, people and other animals which are rarely more than $100-150 \mathrm{~mm}$ tall, and sometimes as small as $50 \mathrm{~mm}$. Where images were shallowly cut and especially where they occur on horizontal rock surfaces, the detail is often very eroded - sometimes only groups of vertical lines survive, indicating legs of multiple animals. The competence of the carvings range considerably, from simplistic depictions of basic quadrupeds, to beautifully observed, but highly stylised, horses (Figs 9-10). The corpus bears many similarities to the well-known assemblage (Fig. 3) from Foum Chenna (TINo12), which as noted above lies directly alongside TINoo1 (Bravin 2014; Pichler 20oob; Reine 1969; Searight 2001).

The most common components were images of horses and horse and riders, sometimes armed with circular shield or lance and shield - with widespread parallels across the Sahara and as far south as the Niger Bend (Amara 2003; Barbaza 2012; Bravin 2020). The execution of the horses varies considerably, from stylised, but immediately recognisable, animals with arched necks of exaggerated scale, pointed ears, long straight narrow muzzles (sometimes oriented vertically down), undulating backs, long straight narrow legs and long down-turned tails (that almost reach the ground) (Fig. ga-b). Some of the most detailed images include indications of hooves and give greater shape to legs, more heft to the fore and hindquarters and even a sense of motion (Fig. 7a). The pecked area of the body and the lines of the legs were sometimes slightly polished or more deeply engraved to remove the roughness of the initial pecking (compare Fig. ga with $9 b$ ) and it is interesting that in some composite scenes the finishing treatment of the horses stands out as markedly superior to other animals featured (Fig. 12). When riders are present, there are also sometimes indications of reins and saddles (see Fig. $7 \mathrm{c}$ ), though the common absence of these elements in most of the imagery is not to be seen as significant. Riders are commonly shown bearing a small 


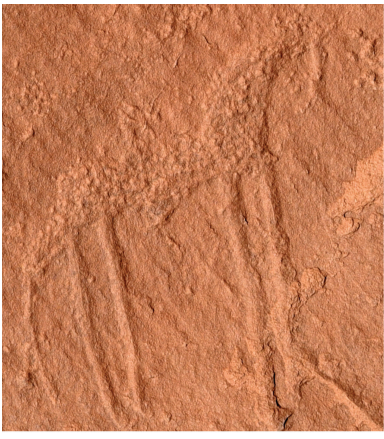

a TIN015 RA 235

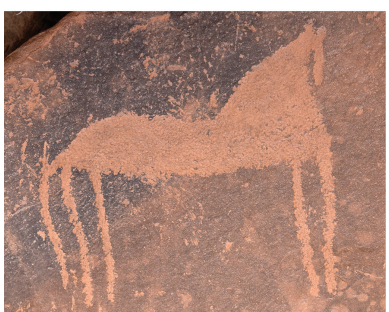

c TIN 015 RA 384

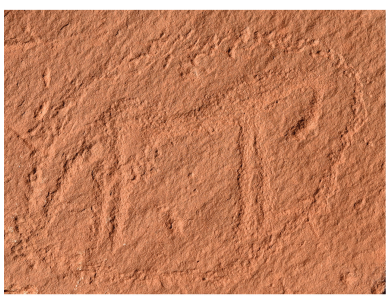

e TIN015 RA 353

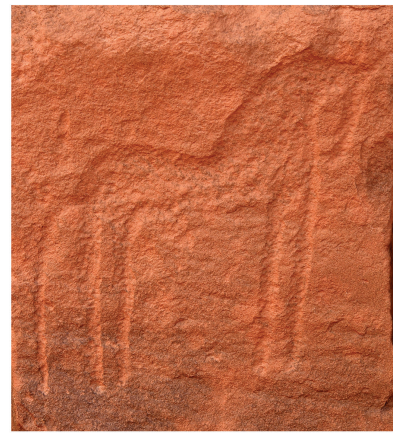

b TIN015 RA 187

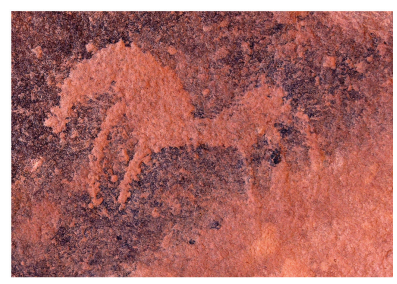

d TIN015 RA 185

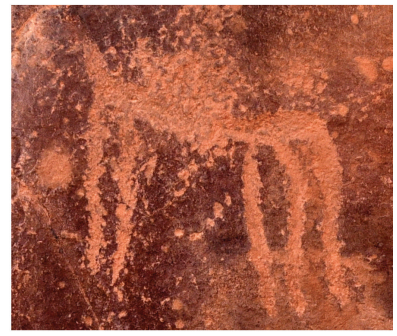

f TIN015 RA 460
FIGURE 9 Stylistic variation in images of horses (most figures are 100-150 mm tall): a) TINo15 RA (panel) 235; b) TINo15 RA 187; c) TINo15 RA 384; d) TINo15 RA 185; e) TINo15 RA 353; f) TINo15 RA 46 o

circular shield on their left arm extended towards the horse's rear and sometimes there are indications of lances held with the reins in the right hand (Figs $7 \mathrm{a}-\mathrm{c}$ and 10).

Two broad groups of simpler versions of horses can be recognised. The first includes some elements of the sinuosity of the horse's form, but with the details highly schematised (Figs ge-f and 1oc-d). The simplest versions reduce the horse's form to a series of straight pecked lines - body, four legs, long tail, neck/head (Fig. 13a, RA panel 13). As we shall see, there are also many unidentified quadrupeds in the corpus, which most likely were highly simplified horses of this type, but with such images it is generally only certain that a horse was intended where there is an additional cross form on top, indicating a rider (Fig. 10e-f). This range of stylistic depictions was present at both our sites (sometimes side by side on the same panel or rock), suggesting either a long period in which imagery was executed, a wide range of competence employed contemporaneously and/or a lack of concern with stylistic consistency.

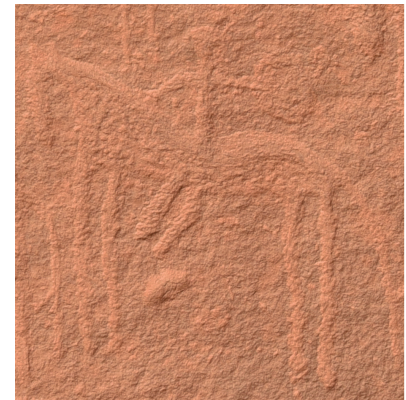

a TIN015 RA 53

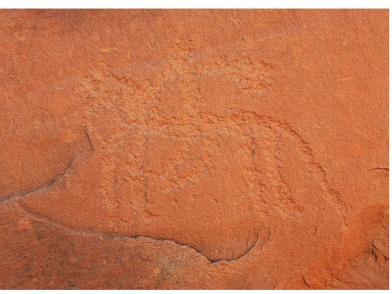

c TIN015 RA 501

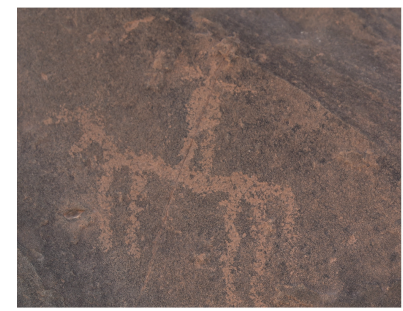

e TIN015 RA 125

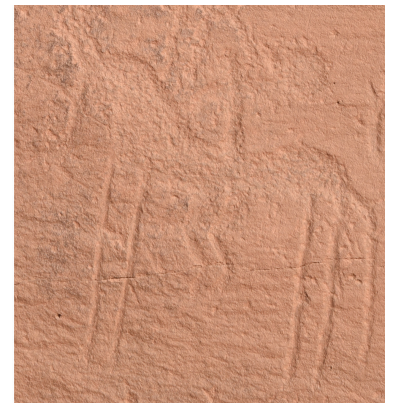

b TIN015 RA 201

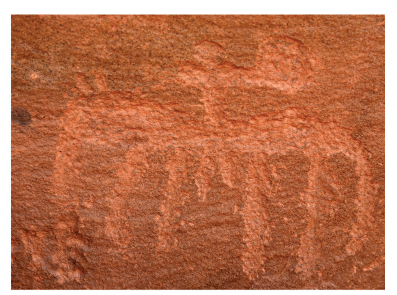

d TIN001 RA 15

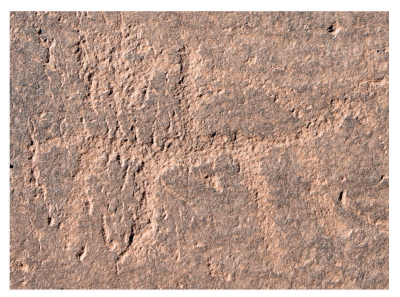

f TIN001 RA 6
FIGURE 10 Stylistic variation in images of horse and rider panels (most figures are 100-150 mm tall): a) TINo15 RA (panel) 53; b) TINo15 RA 201; c) TINo15 RA 5o1; d) TINoo1 RA 15; e) TINo15 RA 125; f) TINoo1 RA 6

Differences in patina may give an indication of a longer chronology (as Reine 1969 proposed), but the formation of patina also appears highly variable, depending on the exposure to the elements, orientation of the stone and the granularity of the rock type. The engravers sometimes seem to have selected rock surfaces that were heavily patinated and sometimes chose more freshly broken surfaces to work on, adding further difficulty to assessing degrees of patination (compare Fig. 9a-b, e and $9 \mathrm{c}-\mathrm{d}, \mathrm{f}$ ). Camels (easily identifiable by their long necks and prominent domical body/hump mass) occur alongside the horses, though in lesser numbers, and in some cases appear to be integral to scenes also featuring horses (Fig. 11a).

Some of the more complex images with horses were evidently hunting scenes, and a few different types of wild animals were noted here (Figs 11b, d-e and 12a-b). These animals are sometimes represented very schematically, rather than naturalistically, but even in the simplest form of engravings (stick representations) there was 


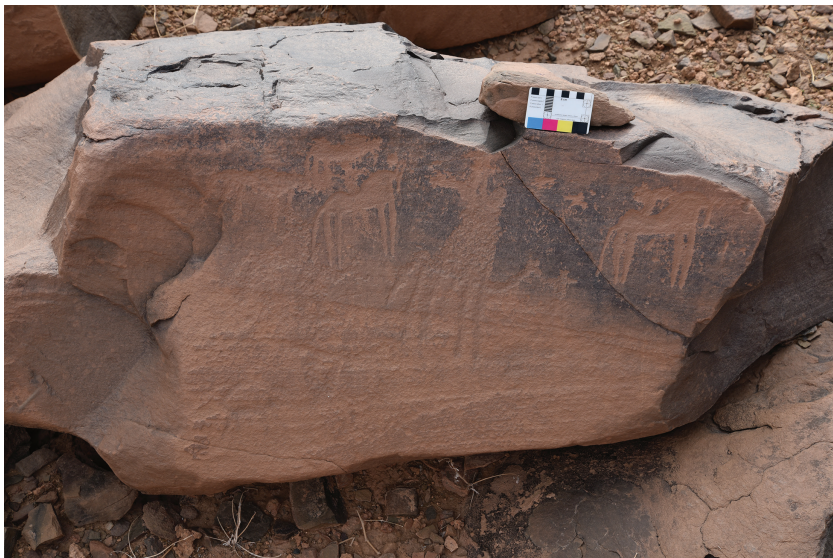

a TIN015 RA 71

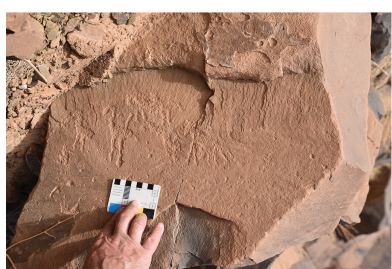

b TIN015 RA266

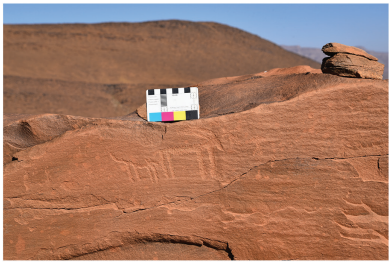

d TIN015 RA 39

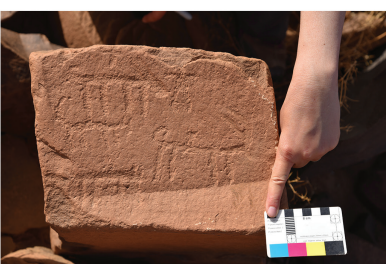

c TIN015 RA 333

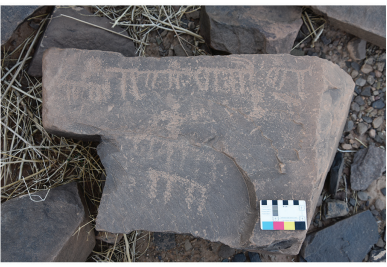

e TIN001 RA 33

FIGURE 11 Examples of some other animals depicted in rock art: a) TINo15 RA 71, a camel being led by a person and accompanied by two horses with riders; b) TINo15 RA 266, two riders on horseback hunting a group of ostriches; c) TINo15 RA 333, two wild ungulates with long horns, a human figure and two possible large felines, with curled tails; d) TINo15 RA 39, a dog with elongated muzzle following a wild ungulate; e) TINoor RA 33, (top row l-r) dog(?), ostrich, dog, wild ungulate, horse, (centre) horse with rider facing left, (bottom) large feline with curved tail

generally some attempt to differentiate between species (see Fig. 11e). The main prey depicted appears to have been ostrich, identifiable as two-legged figures with long necks (though Searight 2001: 128, suggests some of the birds at Foum Chenna were bustards), and wild ungulates, identifiable by the presence of long, thrown-back and sometimes curved horns (Barbary sheep are perhaps the most likely subject, but again the schematic nature of the imagery could also encompass a range of gazelles, oryx and hartebeest under this category). Large cats were also noted, generally identified by their shorter legs and necks, long curved tails, and sometimes pointy ears - it is not possible to discriminate between leopards and lions in the schematic images. Probable hunting dogs with long

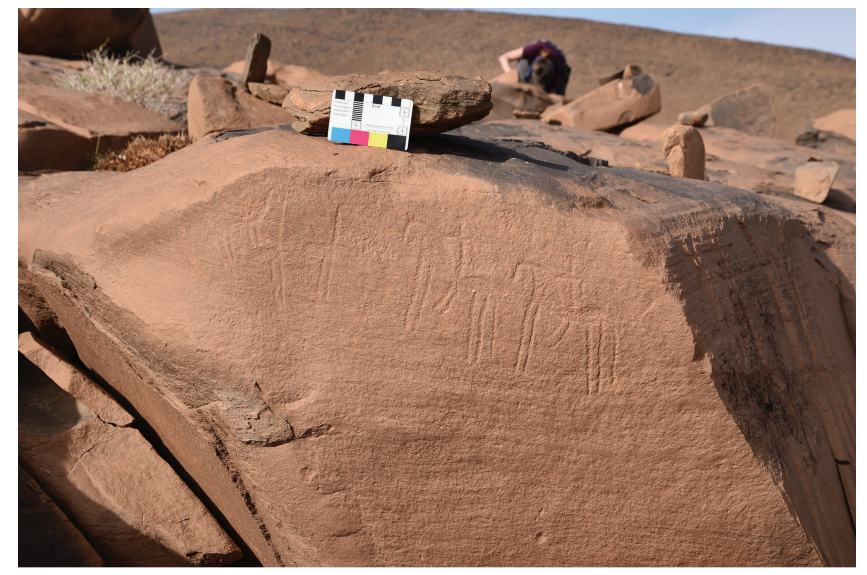

a TIN015 RA 190

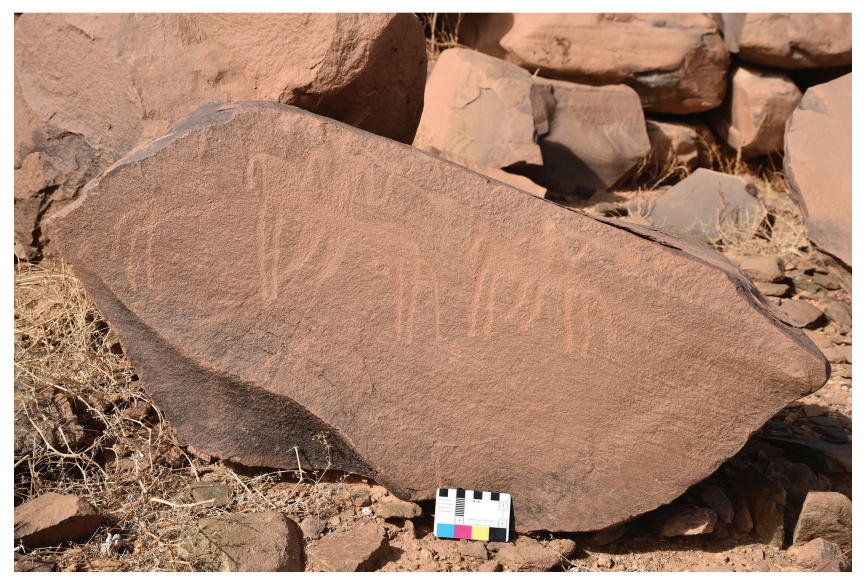

b TIN015 RA 253

FIGURE 12 Hunting scenes: a) TINo15 RA 19o, two riders approach a group of four ostriches; b) TINo15 RA 253, two hunters on horseback surprise a grazing ostrich

snouts and straight or slightly upcurled tails were also noted in a few instances.

With material of this sort, often poorly executed in the first place and somewhat eroded by passage of feet or by the elements, there must inevitably be a degree of uncertainty in our identification of elements in the scenes. While we have had to consign quite a number of images to an 'unidentified quadruped' class, we are reasonably confident that our close examination of the imagery in the field and sometimes in different light has allowed us to reach justifiable conclusions in the majority of other cases. The numbers and percentages presented below are thus not exact, but probably not too far from reality either. We hope to refine interpretation and achieve greater certainty through continuing work at the sites.

\subsection{TINoor}

Across the site there are 55 rock art panels (of which eight have only indistinct shapes or pecking) and a total of 103 distinct elements, counting horses with riders as two 


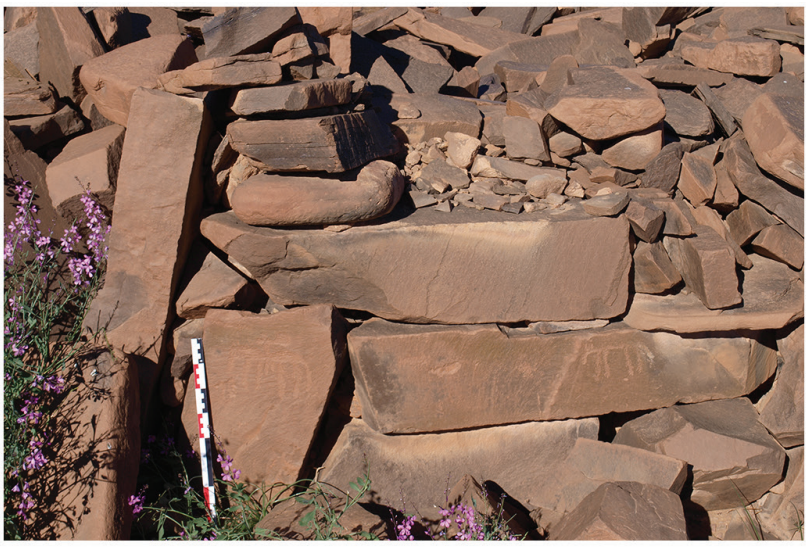

a TIN001 RA15 (I) and $13(r)$

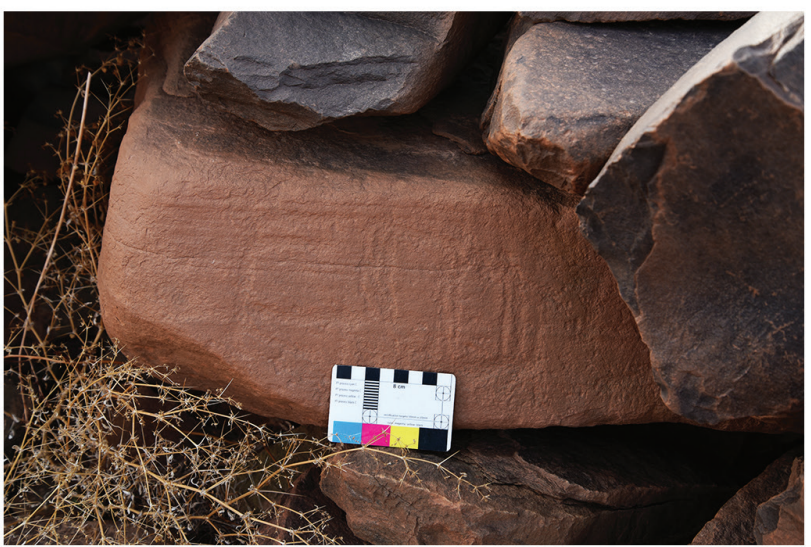

c TIN015 RA 398

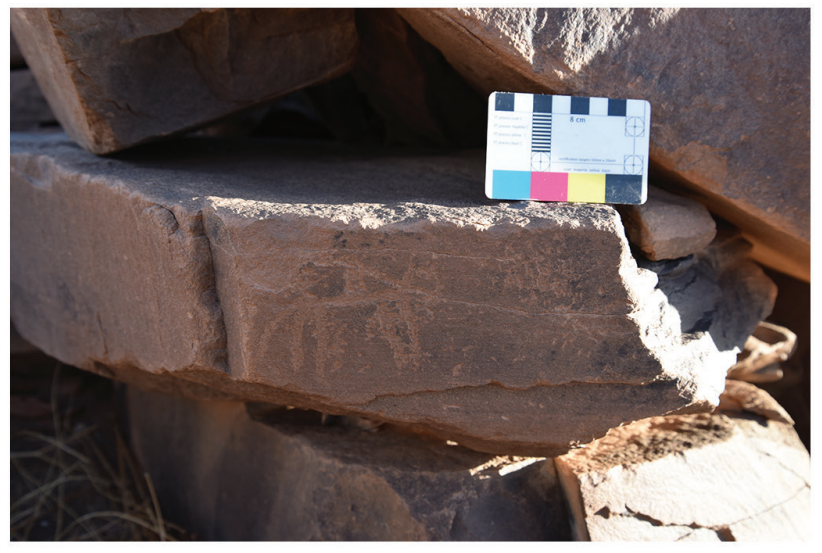

b TIN001 RA 9

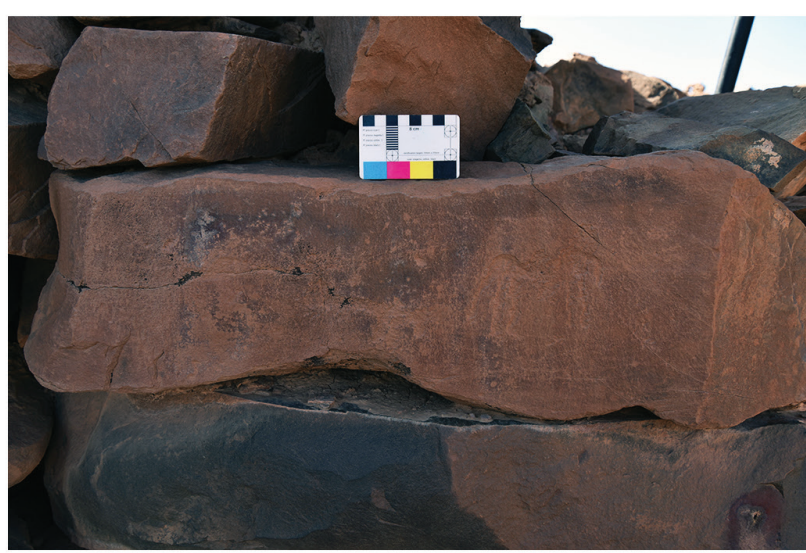

d TIN015 RA 461

FIGURE 13 Engraved figures on blocks used in drystone masonry of settlement structures: a) TINoo1 RA 15, horse and rider (left) and RA 13, quadruped/horse (right), with faint trace of a further pecked image on block above (RA 14); b) TINoo1 RA 9, horse and rider; c) TINo15 RA 398, faint perpendicularly superimposed images of horse and other quadruped; d) TINo15 RA 461, horse and a cruder quadruped

elements, a horse and its rider (Fig. 8a and Table 1). Most of the panels were stylistically simple when compared to TINo15 (see below), small in scale and involved only one or two elements. Horses were the most common element, with eight examples of horses on their own and 21 horses with riders ( 28 percent of identified elements). There are in addition 33 examples (31 percent) of quadrupeds that are so basically delineated in 'stick form' that attribution to species is impossible, though as discussed above, it is probable that a high percentage of these 'quadrupeds' were crude representations of horses too. At any event, allocating just two thirds of the quadrupeds to the horse category would make horses account for c.5o percent of the imagery. Human figures account for 23 percent overall, with 21 rider figures, and a further three representations of standing human figures. A small number of other animals were identifiable (see Fig. ne for an example), including five camels, two wild ungulates, four ostriches, two dogs and one big feline, but overall totalling only about 13 percent of elements.

The distribution of horses and horse and riders are broadly similar (Fig. 16a), with all of the former and all but three of the latter concentrated in the main habitation area with the greatest concentration at the summit of the site where there was a possible burial monument (see Fig. 4a). Of the five depictions of camels (all riderless), three of these are found in a small cluster beyond the northern end of the site, with one figure in the second enclosure and one in the main habitation area (Fig. 18a). The other identifiable animals were mostly found in the first and second enclosures with only a dog and an ostrich found within the main habitation area (Fig. 19a). There are three crosses found in or on the walls of the main habitation area. Finally, there is an Arabic inscription which reads "الغرب" [perhaps 
'west' - though one reviewer pointed out to us there are other meanings of the term that relate to horses] on rubble from the boundary wall of the second enclosure although this looks to be of relatively recent date.

The majority of the rock art panels (31 of 55 panels) are located in the main habitation area of the site with a further six panels on the collapsed walls outside the main gate on the north-west side (Fig. 8a). Within the settlement, the panels have a largely linear distribution along the main street leading to the summit of the hill. The placement of carvings on different types of stone surfaces is also revealing (Fig. 21a). Only 11 panels were on in situ masonry, but eight of these were in locations facing this street with the other three in one of the larger habitation enclosures (Fig. 13a-b). There are three further panels in the rubble of the upper enclosure wall and four in the wall of the second highest enclosure wall (two in situ). There is a single image of a person with a shield on a bedrock surface in the fourth enclosure and a further three clusters of images on boulders and rubble on the slopes to the north of the site. A few panels were found on blocks related to two of the cairns that are distributed over the north part of the site. Overall, almost the entirety of the corpus ( 50 of 55 panels) was on smallish blocks suitable for building or wall construction, in contrast to the imagery in the wadi below (TINo12), which was generally carved on larger boulders and exposed rock surfaces. Of the in situ masonry, 10 of the 13 images were right-side up, with two images orientated sideways and one too indistinct to record an orientation. Of the 19 instances in which imagery appeared on the vertical surfaces of masonry rubble, 15 were orientated right-side up including at least one example (RA panel 40) in which the figures were orientated at an angle to the flat surfaces of masonry, but parallel to the ground surface, therefore raising the possibility that it was created after the erection of the structure. The overall impression is that the rock art assemblage on TINoor was differentiated from the open-air rocky cliff face below (TINo12) in terms of the generally small stone slabs it was engraved on, but not its iconographic repertoire. The incorporation of rock art into the spatial fabric of the settlement was intentional and purposeful, not simply the product of random reuse of blocks that had been engraved at an earlier date. To the extent that a few engraved blocks were inverted within structural walls, these can be accounted for by the observation that there were at least two building phases and the rock art seems to relate to the first of these. The prominent alignment of horse imagery along the main alleyway of the settlement and the cluster around the possible funerary cairn at the highest point of the site suggests possible sacred associations.

\subsection{TINo15}

This site is much richer in rock art: in total we recorded 518 individual panels of rock art which depict 1,491 distinct figures (there are a further 34 indistinct peckings of one form or another). The material is distributed across all areas of the site, including the outer enclosure, main habitation area and the plateau and enclosures to the south. This corpus is sufficiently large to explore the different contexts and distributions of different rock art forms and to give some sense of the chronology of the creation of the rock art.

The hundreds of panels identified come from all areas of the site, but around two thirds are found at the south end in the open area. Here, two particularly dense clusters can be identified, suggesting that the engraving activity was, in part at least, spatially focused (Fig. 8b and Table 1). Both areas contain imagery pecked on exposed bedrock formations as well as on larger standing boulders, some of which may have been arranged in rough ovals - though these were partially disturbed at a later date and a number of boulders were tipped over leaving some of the larger compositional scenes upside down. It is possible that some of these larger scenes originally served as focal points in a 'sacred' area, with a plethora of other images of individual figures or small-scale compositions added on surrounding rock surfaces (for typical contexts see Fig. 14). The engravings were sometimes pecked through the dark grey patina of long exposed rock surfaces, but in many cases a preference seems to have been shown for working on more recent breaks in the rock exposing the sandy brown colour of the natural rock (Fig. 14c, RA panel 40).

As already noted, the motifs range from very simple stick-like figures, to well-formed stylised figures. The dominant theme was once again horses (Figs 7, 9-10, 14-15), with at least 756 individual horses identified among the panels (51 percent of the identified elements), 234 of which had riders (16 percent) and a further three horses were led by people (Fig. 16b). Careful recording of left- and right-facing orientation of the horses showed no significant preference for one over the other. There are also 273 further unidentified quadrupeds (18 percent), many of which were again very likely to have been crude representations of horses. Of 47 camels identified ( 3 percent), four had riders and one was being led (Fig. 11a). People standing on their own were relatively rare, with only 14 instances noted; however, some of these were clearly significant figures, shown at enhanced scale or bearing weapons. The total human representations, including the horse and camel riders, numbered 253 (17 percent), with 72 (5 percent) depicted bearing 


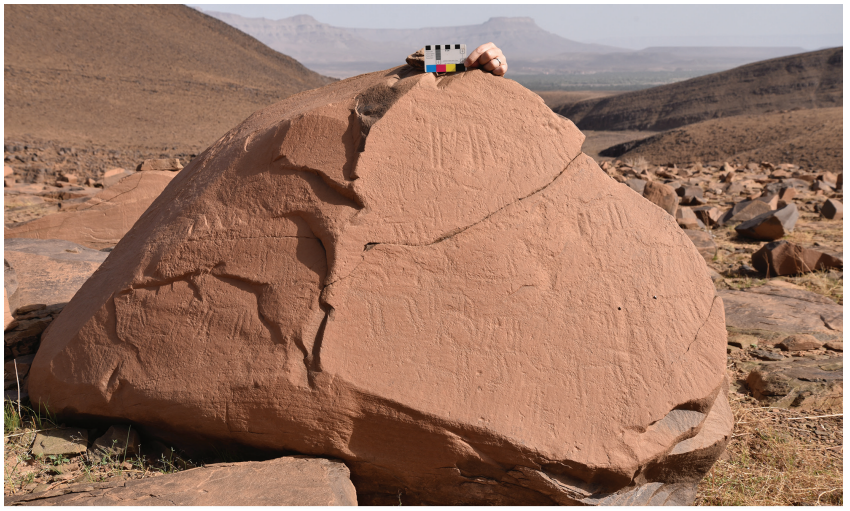

a TIN015 RA 203

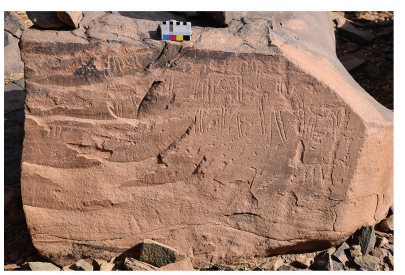

b TIN 015 RA 215

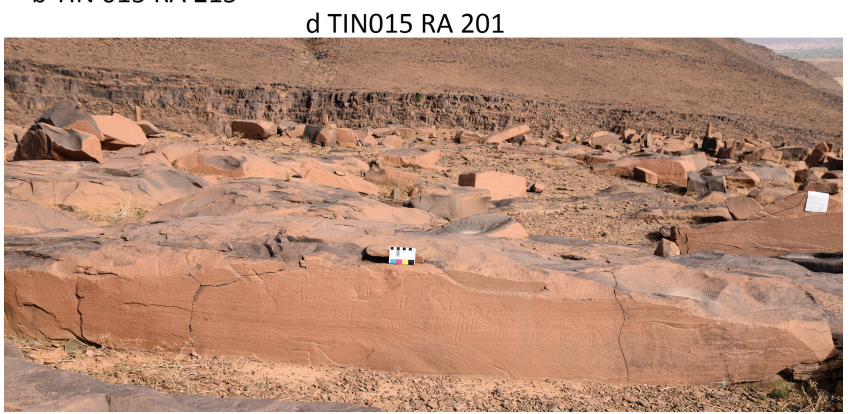

FIGURE 14 Typical contexts on upper plateau area at TINo15 for larger assemblages of imagery: a) TINo15 RA 203, multiple engraved horses (some with riders) and two horned ungulates on large boulder; b) large group of horses (some with riders) on a large boulder (note also several additional crude quadrupeds and, in eroded lower left part of rock face, further vestigial figures); c) TINo15 RA 40, at least 20 horses cut on faces of two fracture scars of a large boulder; d) TINo15 RA 201, 'procession' of horses and other animals on vertical face of tabular bedrock formation, differences in style select several interventions

arms. Of the horsemen, 6o bore a small circular shield, five a lance and shield (see Fig. $7 \mathrm{c}$ ) and three a lance alone (Fig. 12a) - though the eroded state of many of the simpler engravings may well conceal further examples. Two of the standing figures also bore lance and shield and a further two just the round shield (Fig. 15). A series of scenes with multiple linked elements appear to represent people on horseback accompanied by dogs and hunting a range of animals: ostrich, wild ungulates, leopards or lions (Figs 11-12).

Beyond horses, camels, and dogs (and a possible donkey), there were no other domesticated animals. It is perhaps worth noting that some of the equids have especially

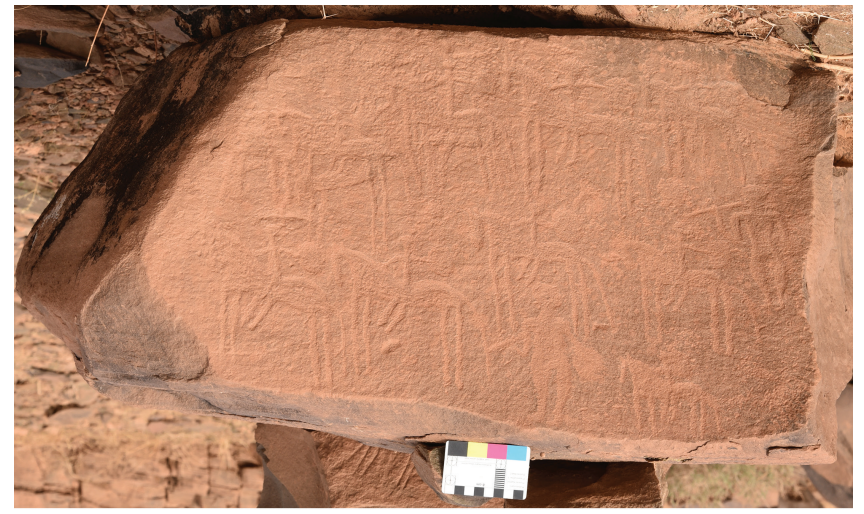

a

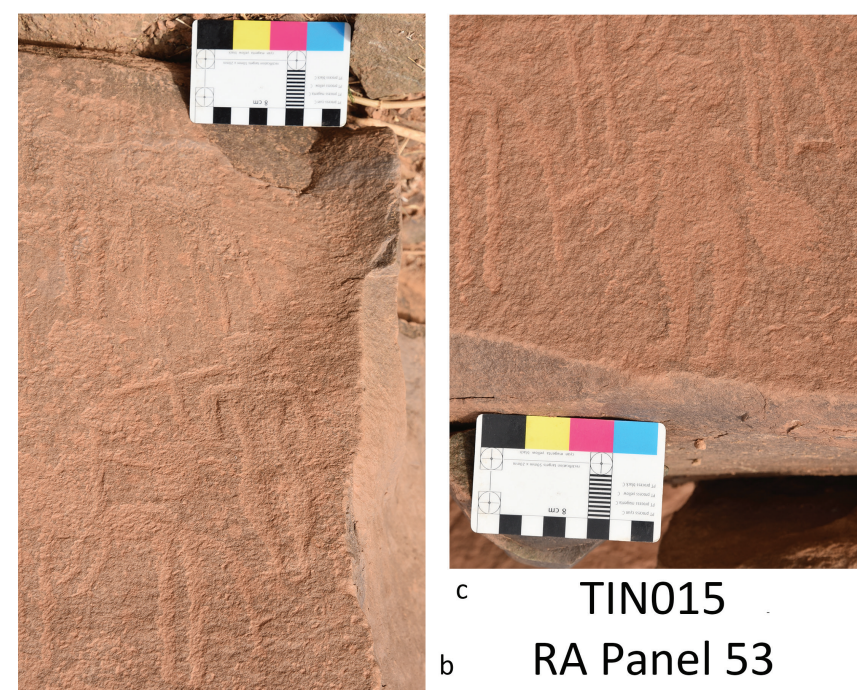

FIGURE 15 TINo15 RA (panel) 53: a) the overall composition on a now upside down boulder showing multiple horse and rider figures around two standing individuals; b) standing figure to right of scene holding a lance; c) larger standing figure from centre bottom of scene in orant pose with a spear in right hand and a shield hanging from left arm

prominent ears and are potentially mules, which could raise the possibility that some of the scenes depict caravans, though there is no evidence of them carrying loads. The absence of definitive examples of cattle, sheep, goat or pig is significant. There were also no signs of anything resembling agricultural or domestic scenes. The only other animals positively identified were three possible snakes, and one scorpion.

The distribution of horses and other imagery is not uniform across the site (Fig. 16b). In the bedrock areas riderless horses make up close to three quarters of equid imagery, whereas in the enclosure and habitation areas of the site the ratio is closer to 1:1 (97:116). The bedrock areas also featured a number of boulders with multiple horses with the largest group of 20 (RA panel 40, Fig. 14a) and c.3o scenes with five or more riderless horses. In the habitation area of the site there are only two scenes with 

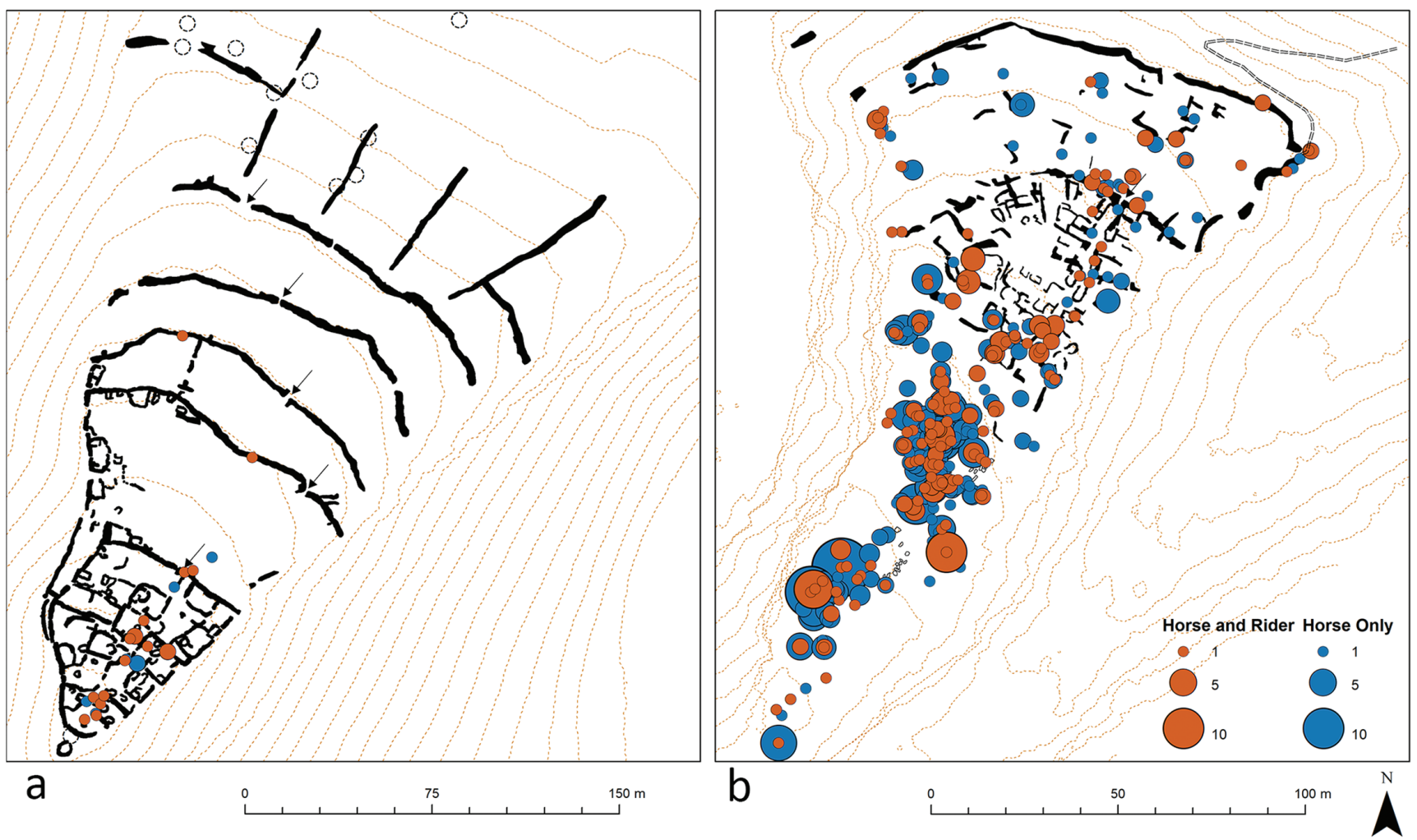

FIGURE 16 Distribution of riderless horses and 'horse and rider' imagery at the two sites: a) TINoo1; b) TINo15

five or more riderless horses. There are only three scenes (all in the bedrock area) with four or more riders, one a group of ten riders and two larger-scale people on foot (RA panel 53, Fig. 15), another scene of four riders and nine riderless horses (RA panel 35) and a further group of four riders, five riderless horses and three ostriches (RA panel 201, Fig. 14d). The last of these scenes seemingly depicts a hunt, but in some cases the identification of a hunt is more ambiguous, especially when horse and riders are more carefully worked than secondary fauna in the scene (for example, RA panel 114). Nonetheless, hunting was certainly an important element in the iconography here (Fig. 17): there are 26 scenes of horse and riders with ostrich $(20)$ or wild ungulates (7) of which 22 are in the bedrock areas and two each are in the south enclosures and the main habitation area.

There are 47 images of camels in total distributed over $3^{2}$ panels (Fig. 18b). These are one of the most evenly distributed image types across the site and they are found in all sectors. The largest group is of four camels in a line (RA panel 192), but the majority of scenes (21) only have one camel often with other figures. Potentially some of these scenes might relate to camel trains or caravans, although there is only a single scene with a led camel (RA panel 71, Fig. 11a, in which a camel, led by a person, is surrounded by two horses and riders and two dogs). Four of the camels have riders (e.g. RA panel 360).

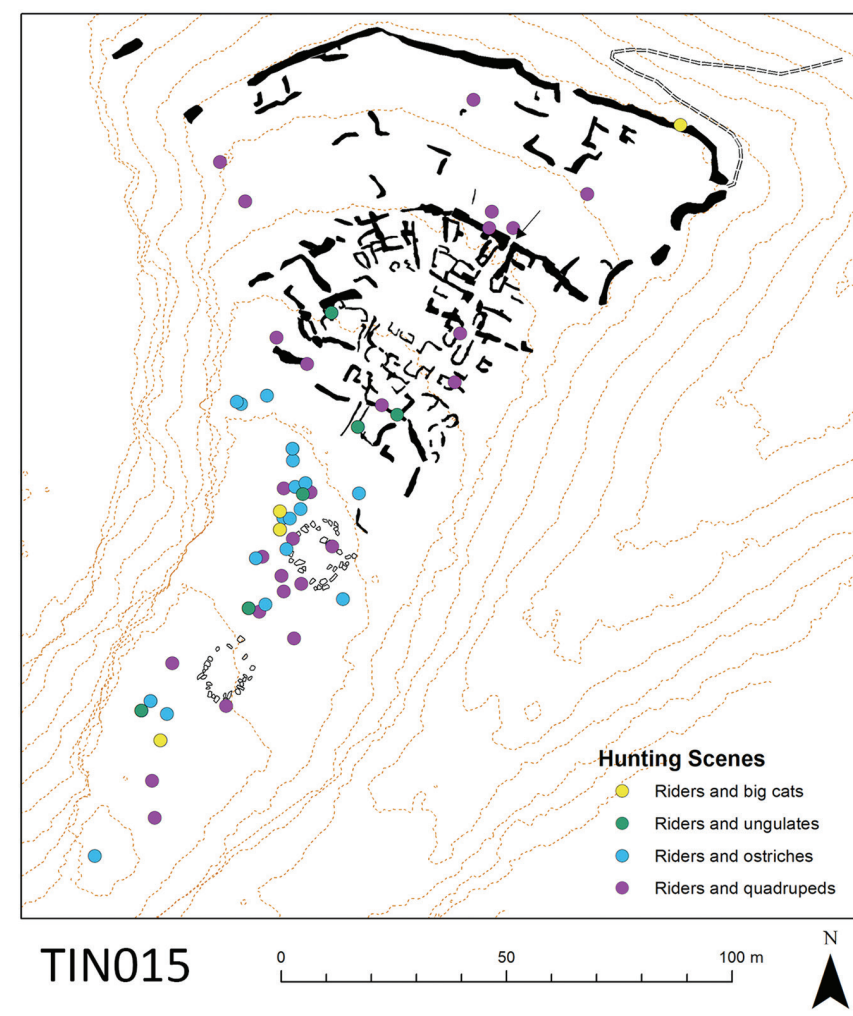

FIGURE 17 Distribution of 'hunting' imagery at TINo15 (the smaller scale of images at TINoor makes unambiguous interpretation of hunting scenes more difficult) 


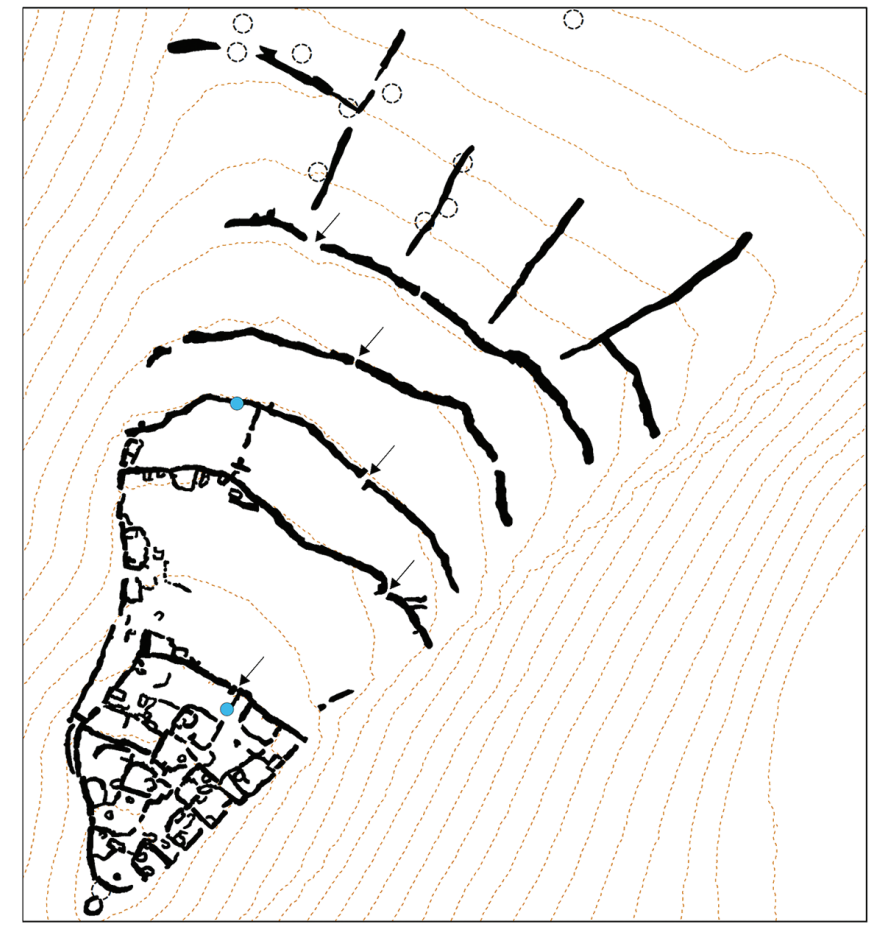

a

FIGURE 18 Distribution of camel imagery: a) TINoo1; b) TINo15

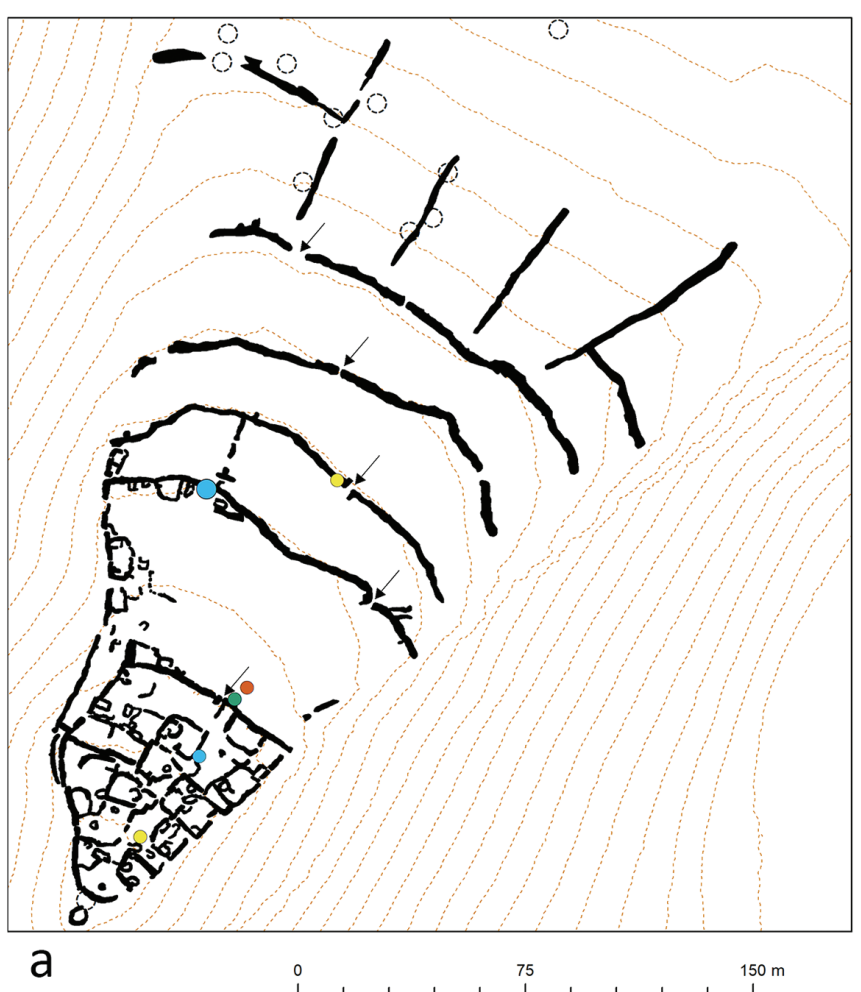

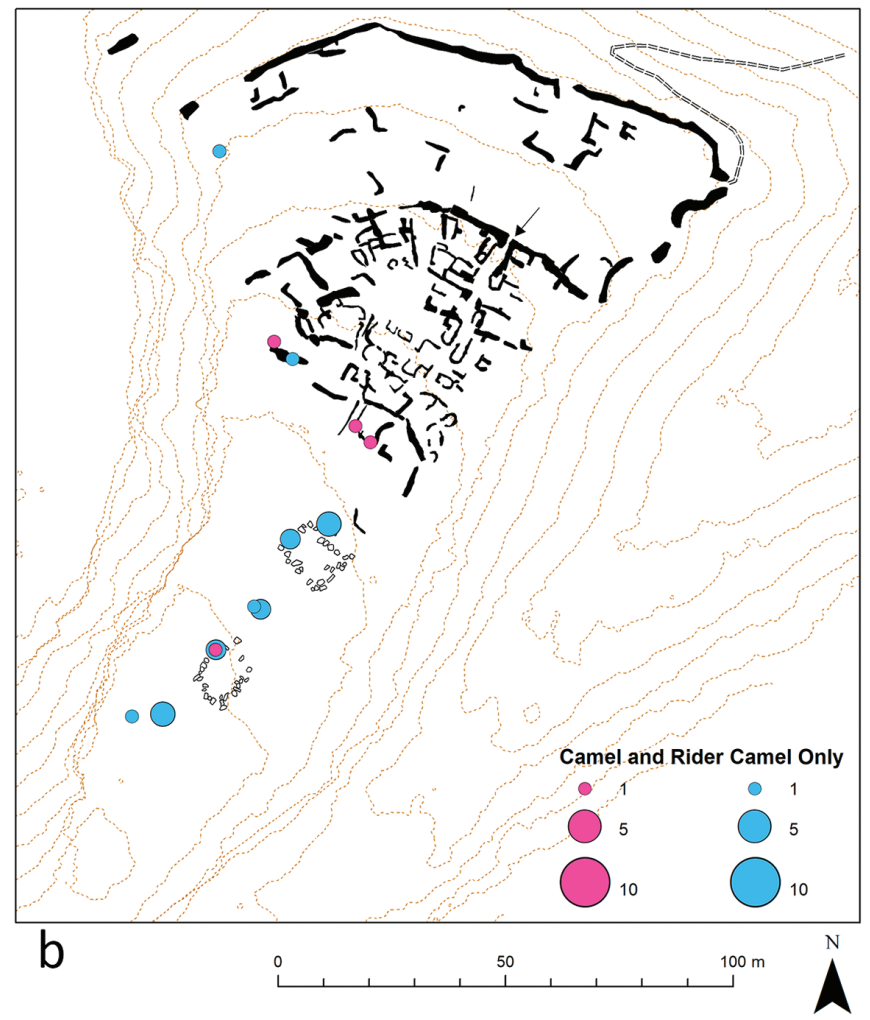

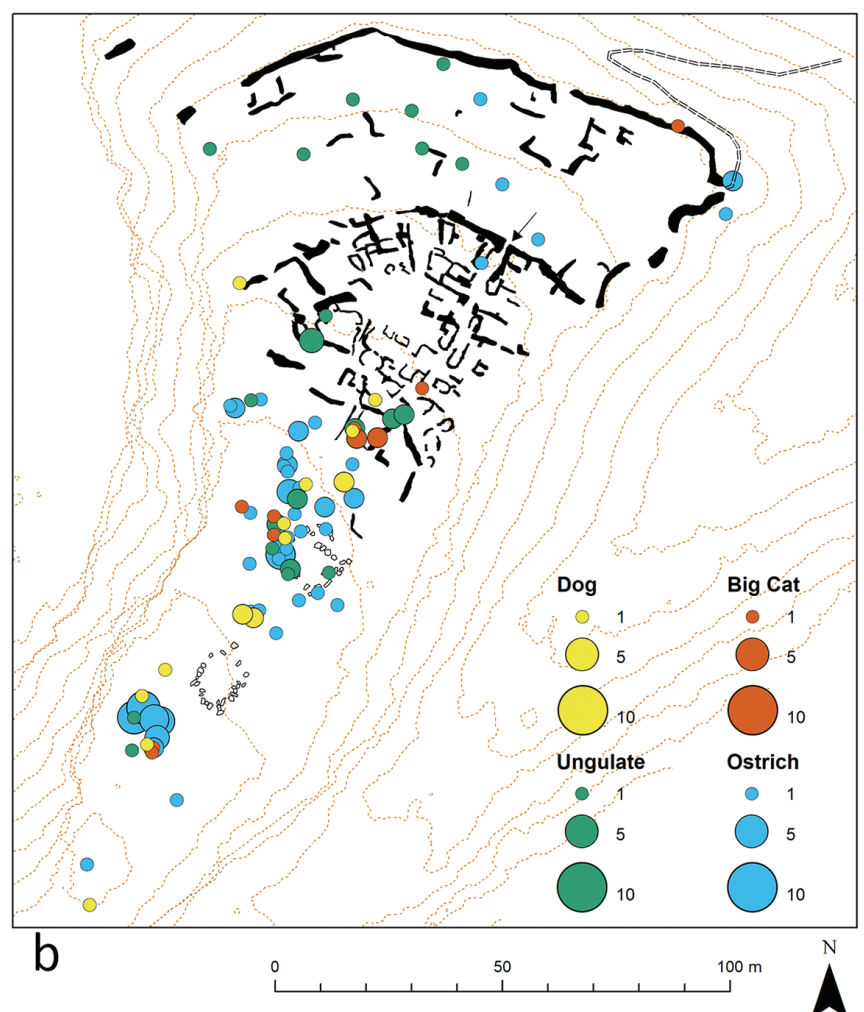

FIGURE 19 Distribution of selected other fauna in imagery at the two sites: a) TINoo1; b) TINo15 


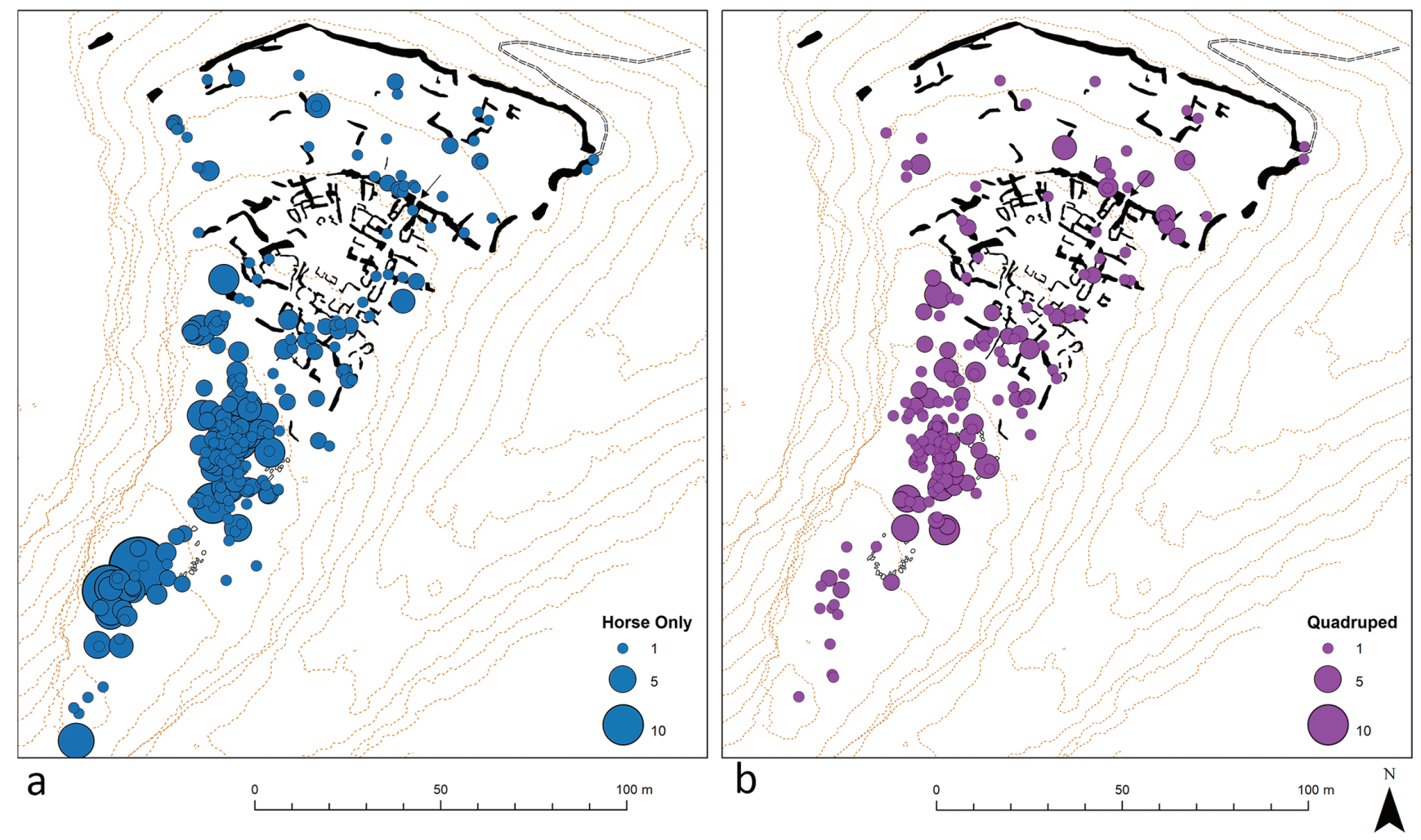

FIGURE 20 Comparative distributions: a) horses; b) unidentified quadrupeds at TINo15
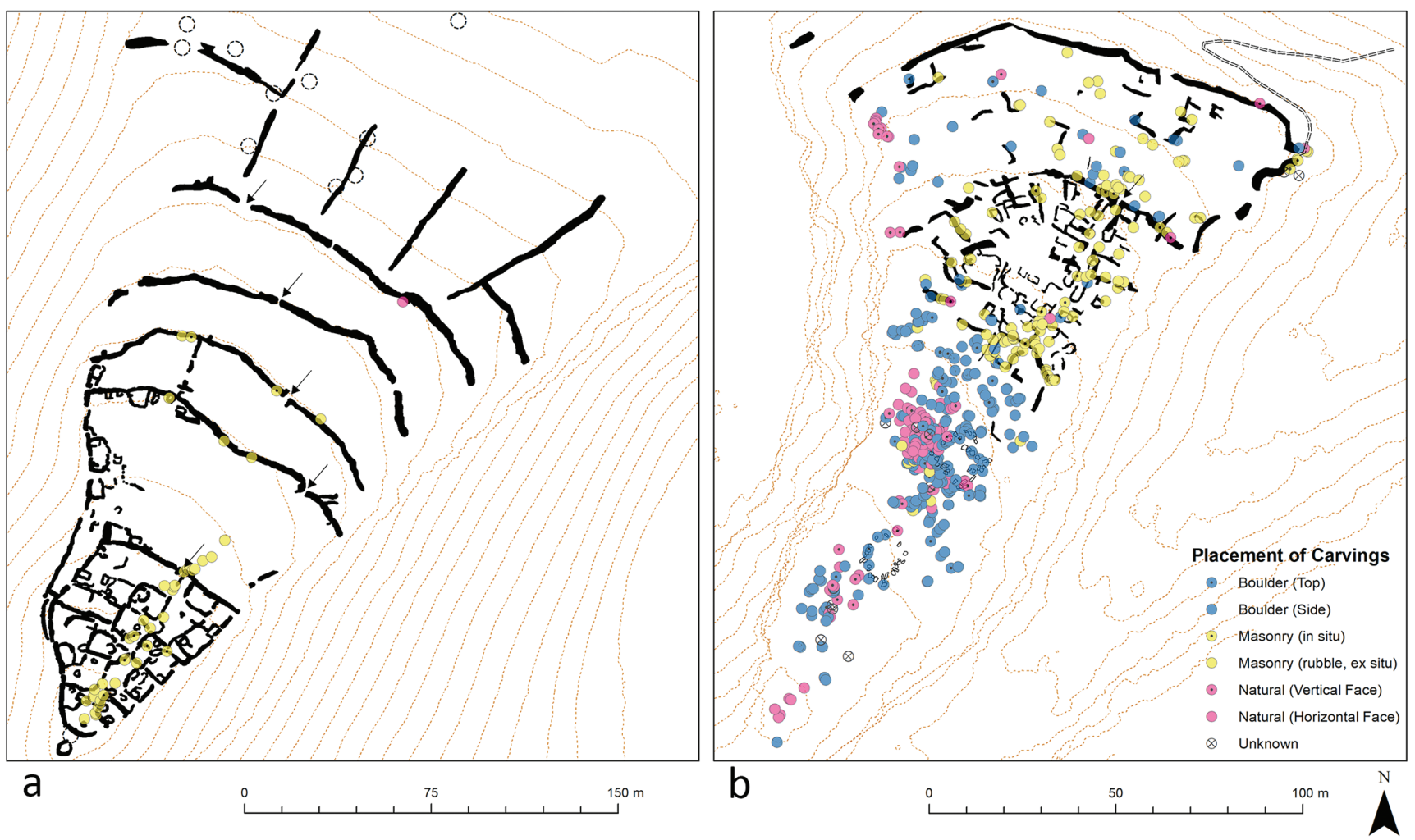

FIGURE 21 Distribution of different placement of carvings (on boulders, on bedrock exposures, on masonry blocks) at the two sites: a) TINool; b) TINo15 


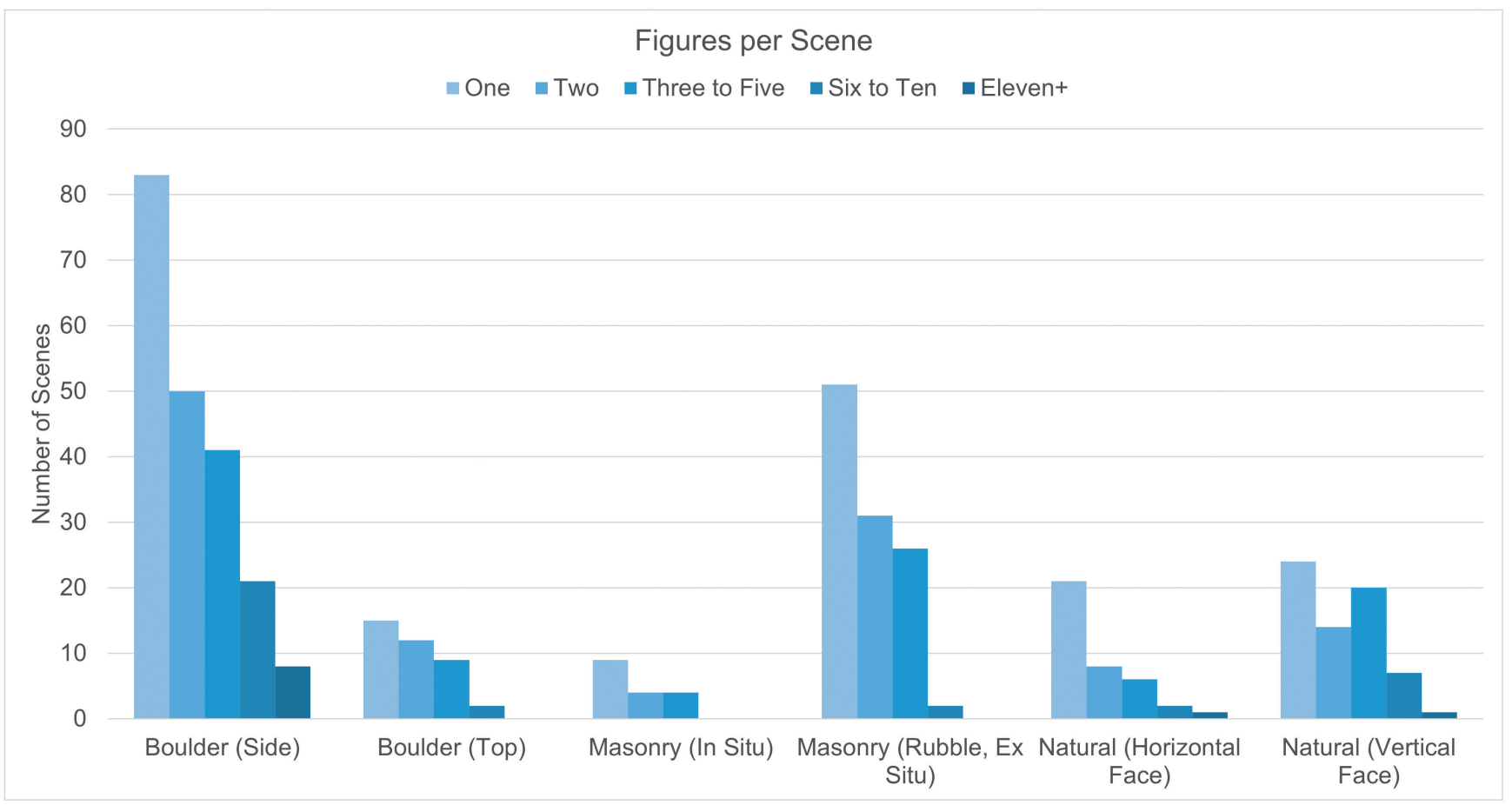

FIGURE 22 Charts showing the varied placement of imagery and numbers of figures on different types of rock surface at TINo15

Similar to camels, the distribution of wild ungulates $(35$ examples, potentially including Barbary sheep, Barbary stag, bubal hartebeest, gazelle, addax and oryx), dogs (16) and large cats (12) stretches across the entirety of the site (see examples in Figs 11b-e and 19b). Dogs are more regularly found alongside horse and riders (7 out of 13 panels) than big cats (3 out of 10 cat figures are found with horse and riders) or wild ungulates ( 7 out of 27 wild ungulates are found with horse and riders) probably suggesting that these are more often domesticated dogs rather than wolves or wild dogs. Ostriches are rather more numerous (77 figures in 48 panels), but much more heavily concentrated in the bedrock areas and to a lesser extent in the enclosure areas with only two instances in the main habitation area. Most of the occurrences are in scenes with horse and riders (20 panels) or riderless horses (15 panels) and they are the sole figure in only 9 panels.

There are 275 unidentified quadrupeds across 175 panels and in 102 of these images they are the sole figure represented. These are therefore a substantial component of the overall corpus. The distribution of these figures is most prominent in the northern and southern bedrock areas and to some extent the main habitation area where there are approximately the same number of riderless horses (Fig. 20). However, their distribution more closely matches the distribution of horse and riders. It is possible that this distribution is a result of the greater wear and natural erosion that scenes in these areas have been exposed to over time, rendering uncertain the identification of a significant percentage of these images as horses or other equids.

Four Libyan inscriptions have been identified all located in the bedrock areas. Neither of two inscriptions found by Pichler and Rodrigue (2003) were located on the plateau of TINo15 (it is possible that they are instead found at one of the valley sites that have not yet been fully catalogued). A single Arabic inscription was found in the north of the site, but this appears of recent date. There are at least 14 individual symbols across the site (their small size makes them quite hard to spot and easily damaged or eroded) - these comprise a range of crosses, spirals and circles. Half of these are found in the upper bedrock area with the rest evenly distributed amongst the enclosures and habitation area.

The varied locations in which engravings were found, whether bedrock exposures, large boulders or small blocks of stone, is revealing (Figs 21b and 22). Around half of the panels $\left(25^{8}\right)$ were carved into large boulders (some over $1 \mathrm{~m}$ tall), 44 on upper surfaces and 214 on the side faces (Figs 11-12, 14-16). As noted already, some of these boulders appear to have been arranged into rough enclosures, while others sat directly on the bedrock. Around 20 percent (111) of images were carved directly onto exposed areas of bedrock on both vertical (68) and horizontal (43) surfaces, especially in two main areas where tabular bedrock was upstanding. There are some impressive 
TABLE 1 The subject matter of the rock art imagery at TINoo1 and TINo15. Each component of a panel is counted separately - so, for example, an image of a horse and rider is counted as one horse and one person. The figures for Foum Chenna (TINo12) provided for comparison are taken from Searight 2001

\begin{tabular}{|c|c|c|c|c|c|c|}
\hline Categories & TINoo1 & $\%$ & TINo15 & $\%$ & TINo12 & $\%$ \\
\hline Horses & 29 & 27.6 & $75^{6}$ & 50.6 & 116 & 21.2 \\
\hline (with riders) & $(21)$ & $(20.0)$ & $(234)$ & $(15 \cdot 7)$ & $(113)$ & $(20.6)$ \\
\hline People & 24 & 22.9 & 253 & 16.9 & 129 & 23.5 \\
\hline (on horses) & $(21)$ & $(20.0)$ & $(234)$ & $(15 \cdot 7)$ & $(113)$ & $(20.6)$ \\
\hline (on camels) & (o) & (o) & (4) & $(0.3)$ & $(10)$ & $(1.8)$ \\
\hline (on foot) & $(3)$ & $(2.9)$ & $(14)$ & $(0.9)$ & $(16)$ & $(2.9)$ \\
\hline (with weapons) & $(10)$ & $(9 \cdot 5)$ & $(72)$ & $(4.8)$ & $(124)$ & $(22.6)$ \\
\hline Camels & 5 & 4.8 & 47 & 3.2 & 18 & $3 \cdot 3$ \\
\hline (with riders) & (o) & (o) & (4) & $(0.3)$ & $(10)$ & $(1.8)$ \\
\hline $\begin{array}{l}\text { Wild Ungulates } \\
\text { (Barbary Sheep, } \\
\text { etc.) }\end{array}$ & 2 & 1.9 & 36 & 2.4 & 35 & 6.4 \\
\hline Ostriches & 4 & 3.8 & 74 & 4.9 & 29 & $5 \cdot 3$ \\
\hline Dogs & 2 & 1.9 & 16 & 1.1 & 5 & 0.9 \\
\hline Big Cats & 1 & 1.0 & 12 & 0.8 & 27 & 4.9 \\
\hline Donkeys & $\mathrm{o}$ & 0.0 & 1 & 0.1 & o & 0.0 \\
\hline $\begin{array}{l}\text { Unidentified } \\
\text { Quadrupeds }\end{array}$ & 33 & 31.4 & 273 & 18.3 & 130 & $23 \cdot 7$ \\
\hline Scorpion & o & 0.0 & 1 & 0.1 & o & 0.0 \\
\hline Snake & o & O.० & 3 & 0.2 & o & 0.0 \\
\hline $\begin{array}{l}\text { Libyan } \\
\text { Inscriptions }\end{array}$ & o & 0.0 & 4 & 0.3 & 21 & 3.8 \\
\hline $\begin{array}{l}\text { Arabic } \\
\text { Inscriptions }\end{array}$ & 1 & 1.0 & 1 & 0.1 & o & 0.0 \\
\hline Enigmatic & 4 & $3 \cdot 9$ & 19 & 1.3 & 28 & $5 \cdot 1$ \\
\hline (Cross) & (o) & (o.o) & (6) & $(0.4)$ & (o) & (o.o) \\
\hline (Spiral) & (o) & (o.o) & $(4)$ & $(0.3)$ & $(\mathrm{o})$ & (o.o) \\
\hline (Circle) & (3) & $(2.9)$ & (4) & $(0.3)$ & (4) & $(0.7)$ \\
\hline (Ground Line) & $(1)$ & $(1.0)$ & $(5)$ & $(0.3)$ & (o) & (o.o) \\
\hline Total & 105 & 100.0 & 1495 & 100.0 & 548 & 100.0 \\
\hline
\end{tabular}

depictions also on the edge of the escarpment, but in general the vertical rock faces that we were able to examine directly below the plateau top were less exploited than the rocky outcrops and boulders on the plateau. Some larger engraved boulders with multiple images noted on the habitation terraces may indicate that the dense rock art also extended further to the north prior to construction of the settlement, with some of these built into building foundations. The final group are on small masonry blocks, with a number surviving in situ as part of walls within the settlements or enclosures (19, see Fig. 13 for examples), but most of these panels were found in areas of rubble where walls have partially or fully collapsed (116), so it is likely that a sizable number of additional small-scale panels lie buried amongst the rubble. The majority of panels on building stones were small and uncomplicated, comprising at most one or two figures. Almost all figures were aligned with the edges of the stone block they had been carved on. That suggests that figures were cut when buildings were under construction or already built. However, there is at least one example of a block no longer in situ where it is highly unlikely that the figure would have been aligned with the ground surface when it was part of the wall. This raises the possibility that at least some figures were either already decorating irregular blocks at the time of construction or were inscribed after the collapse of some structures within the settlement. Given the great stylistic range of the material, it is likely that the site was in use for a considerable period, perhaps exceeding its lifespan as an active settlement.

\section{$5 \quad$ Dating and Overall Interpretation}

Our two sites provide an unusual opportunity to estimate more accurately the date of these corpora of images. We have to consider three possibilities for the date of the carvings in relation to the date of habitation at these sites: 1. that the imagery was older than the settlements and was already present on the site when the habitation zone was created, and the use of engraved slabs as building materials led to the incorporation of imagery into walls;

2. that the imagery was broadly contemporary with the settlements and at least some of the imagery built into walls was engraved onto the blocks after construction;

3. that the imagery post-dated the abandonment of the settlements and was carved on still standing walls, fallen blocks and the bedrock areas at an unknown point in time.

It is, of course, possible that the practices of image production at the sites spanned a longer period of time than the settlements, encompassing all three of the above contexts. For TINoor it seems unlikely that the imagery found on the settlement had been sourced from the Foum Chenna (TINo12) site below, as most images there were pecked into vertical rock faces or on large boulders, rather than the smaller blocks of stone that characterise the images on the site. There was in any case an abundance of stone on the hilltops for use in construction. In the habitation area at TINo15, there are some larger stones incorporated in wall foundations and exposed bedrock faces on which 
structures were built that had imagery engraved on them and which could potentially predate the site. However, at both sites the presence of neat engravings on exposed faces of small blocks incorporated in walls and with the correct orientation in relation to the ground surface gives the impression that the buildings and engravings were contemporary. A concentration of imagery at both sites on either side of the main alleyway through the settlement (Fig. 8) also suggests that the engravings were made specifically to be seen by people passing through the hillfort. As a result, even if some of the imagery present on buildings was reused, the placement of such images seems to have generally been carefully considered and deliberate, implying a strong association with the purpose and meaning of the images. The third possibility, that the engravings postdate the settlements, seems the least likely. The AMs dates obtained from grains of cereals and charcoal from trial excavation at the sites suggest an occupation date around the mid-1st millennium CE. This corresponds well with other indications in the rock art assemblages regarding dating, such as the presence of Libyan script and camels alongside horses (Bravin 2020).

At TINo15 the non-expansion of the habitation area onto the upper plateau of the site is highly unusual in comparison with other Draa NAIA hillforts surveyed by us. The high concentration of horse imagery in this upper area, the complexity of the larger scenes and the recurrent nature of the mass of smaller engravings that surround those, all highlight the exceptional nature of what went on there. Though other possibilities cannot be excluded, we believe it is most plausibly explained as a 'sacred' focus within a site that overall had a highly unusual/atypical association with such imagery. Though we suggest a degree of zoning of sacred and domestic space existed, the site overall stands out from all the other Draa hillforts explored by us, with the partial exception of TINoo1. Indeed, at TINoo1, the highest point of the site may also have had a 'sacred' significance, with larger numbers of engravings clustered there close to a possible burial cairn. At TINo15, the two high density clusters of horse related imagery on rock surfaces also included some highly unusual, larger and more complex scenes on standing boulders. There are also some small horizontally-cut, rounded holes in some vertical rock faces close to the settlement that may have had an offertory purpose (similar features have been noted at TINo27, the rock art site below TINo15). Both the concentration of imagery at these locations and the repetitive and recurrent nature of the execution of these engravings attests to the fact that these were highly symbolic locations within the wider landscape. Some connection with the people who occupied the hillforts thus seems impossible to avoid. In the next section, we shall explore in more detail what were the potentially 'sacred' connotations of the rock art.

Although there is, of course, limited possibility of achieving a consensus at this distance in time and social space from its originators, a first question to ask is what was the social purpose of these rock engravings? There is much debate about the meaning of rock art across its several phases in the Sahara and the function served by the act of engraving or painting (Barnett 2019a; Le Quellec 1993, 2004). The Libyco-Berber phase imagery is to some extent the poor relation of the generally more naturalistic and ambitious Neolithic rock art and has received less attention. However, schematic representations of horses (and their riders) are a pan-Saharan phenomenon (indeed they are a distinctive regional variation of one of the most ubiquitous of rock art motifs found on every Continent bar Antarctica).

Barnett's sophisticated analysis of a large assemblage of imagery from the Wadi al-Ajal in southern Libya has shown that rock art of all periods had significance within natural and cultural landscapes (Barnett 2019a, 2019b; cf. Bradley 200o). The images in the Wadi al-Ajal are spread along a $5^{\circ} \mathrm{km}$ length of the wadi, with few gaps of more than a few kilometres length. However, density plots indicate that there was significant clustering at select locations (Barnett 2019a: 222-23). Across time, the densest clusters of imagery correlate with significant natural features and locations of social importance. Much of the Horse style and Camel style imagery appeared at the same locations favoured with earlier carvings (Barnett 2019a: 247-77). Some of these can be related to water sources (springs and rock pools/glet), rock shelters and topographical nodes (passages obligés, headlands, intersections of routeways, etc). A point of considerable interest from this Libyan comparative example is that the contemporary settlements and cemeteries related to the broad phase when the Horse and Camel imagery were created were in general not favoured as sites for engravings. The one exception is the hillfort of Zinkekra, already mentioned at the start of this article and to which we shall return shortly.

It seems a priori logical that similar factors applied to other areas of the Sahara given the underlying similarity in the iconography of the various phases. Comparison with the greatest concentrations along the wadis in which TINoo1 and TINo15 sat also suggests that this distribution was not random or directed at every convenient rock face. Indeed, plenty of promising looking rock faces along these wadis are entirely unmarked. In both instances there were particularly large groupings on the vertical rock faces on the left side of the wadis at the point where they emerged 


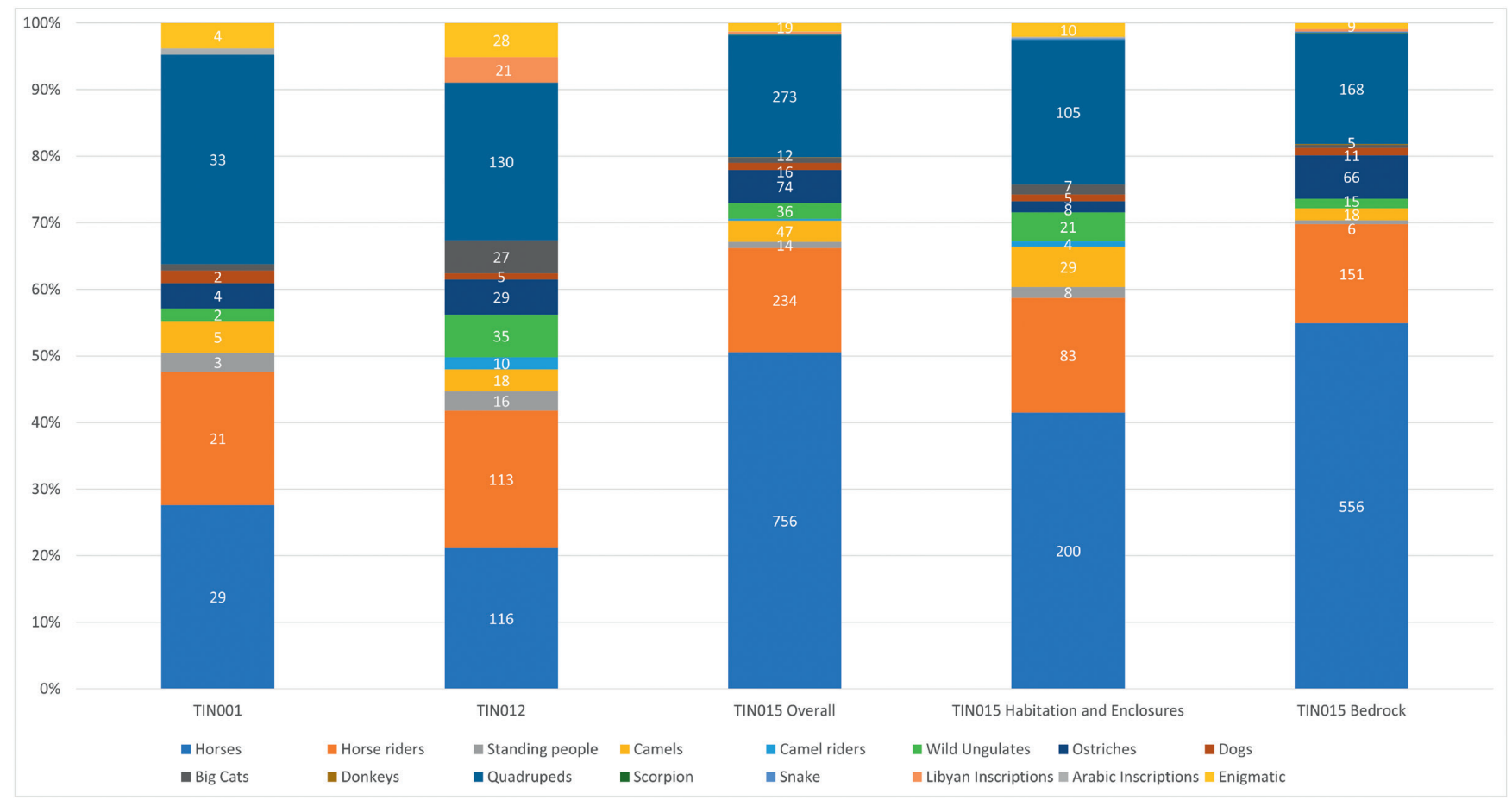

FIGURE 23 Charts showing distribution of different sorts of imagery at TINoo1, TINo12 and TINo15

out of the Jebel (hills) - that is, in a gateway or liminal location where they would be observed by people entering or leaving the Draa valley (TINo12, TINo27). TINo12 also marked the location in the valley directly below the hillfort TINoo1, while TINo27 and TINo28 can be seen as sporadic markings along the approaches to TINo15 from the north and south. Moreover, although the components of the rock art imagery and iconography were similar across all the sites in the Tinzouline areas, the significance of these locations and the purpose of the engravings may have varied.

The wide Saharan distribution of NAIA rock art and in particular images of horses and horses and riders strongly suggests some underlying cultural beliefs and significance (Barbaza 2012; Le Quellec 2004 for associations with exogenous mythologies). The horse was of course an extraordinary and transformative animal in the vast and sparsely populated areas of the Sahara and its fringes (Daumas 1968). In the Sahel it played a central role in slave raiding and the political economy of many sub-Saharan states (Law 1980; MacEachern et al. 2001; Webb 1993). As in other areas of the world it is unsurprising to see that human communities quickly came to represent it in iconographic displays, supplanting other domestic animals. Mitchell's (2015) analysis of the impact of the horse on historical indigenous societies highlights some of the many varied ways in which representations of horses were used to commemorate raids, battles and hunts (e.g. by the Apache and the Niitsitapi), as markers (e.g. by the Comanche nation), as part of seeking spiritual help (by the Lakota) or as a manifestation of rain (by the AmaTola of South Africa). Furthermore depictions can be seen to hold multiple meanings at the same time. The evidence provided in this article, both fits into this frame but also remains distinctive for the focused, high-density and repetitive acts of engraving and the association with habitation at our two sites, which are themselves highly atypical of other contemporary sites we have investigated in the Draa, North Africa or the Sahara. It thus seems likely to us that the people who carved the imagery in the Draa could be considered (in Mitchell's terms) a 'Horse Nation', that is a society in which horses played a fundamental role in travel, trade, hunting and warfare, but also cosmologies and belief systems. The exceptionality of TINo15 in particular seems a strong argument in favour of identifying a sacred aspect to this imagery and to the other locations where it was most emphatically produced in the landscape.

A different starting point for interpreting the caballine and cameline phase rock art is to consider what else we know of the Saharan peoples at this time. The regions from which much of the Saharan horse imagery originated corresponds with the northern Saharan territories of people referred to by Greco-Roman sources as the Gaetuli and the Garamantes, and later as the Laguatan and Mauri. Greco-Roman sources allude in several places to horsebreeding and the importance of equine cavalry among the 
desert and pre-desert peoples of North Africa (for example, Strabo, Geography 17.3.7). In another passage seemingly related specifically to the Garamantes and Gaetuli, Strabo alluded to 100,00o colts raised annually (17.3.19). The heartlands of the Garamantes were the Wadi al-Ajal in southern Libya (mentioned above, see also Mattingly 2003, 2013), while different groups of Gaetuli are attested in pre-desert locations from the Atlantic coast to the Greater Syrtic Gulf. These peoples have long been assumed to have been primarily pastoralists (Desanges 1962; Hamdoune 2018: 63, 70-79), but recent work has demonstrated that at the core of these societies were oasis cultivators who were closely linked to pastoral groups (Sterry and Mattingly 202O; Trousset 2012). The transformation of limited refugia into oases following the last dramatic climate change around 5,ooo years ago (Purdue et al. 2018) was accompanied by the spread of animals like the horse, donkey and camel, agricultural crops like cereals, dates, vines and other fruits, and irrigation technologies (Duckworth et al. 2020). Horses were a particularly important innovation, with wide-ranging impacts from the Nile to the Atlantic, from the Mediterranean hinterland to Sub-Saharan Africa (Fothergill et al. 2020). The Libyan script developed for the Berber/Amazigh languages is another important marker of Pan-Saharan social change in the late centuries BCE and early centuries CE and again can be strongly correlated with the development of oasis societies (Fentress 2019). On present evidence there was some time-lag between the development of oases in the central Sahara (early 1st millennium BCE) and in the Moroccan western Sahara, where it seems to have occurred in the early to mid-1st millennium CE (Sterry et al. 2020). Nonetheless, the horse and horse and rider engravings of peoples like the Gaetuli and Garamantes cannot simply be assigned to pastoralist communities, but need to be considered as part of a widespread and significant transformation of Saharan society and economy in this period.

The mounted warrior might well be representative of powerful individuals within these societies. The widespread nature of essentially similar imagery reflects an effective Saharan koine based on the interconnectedness of oasis and pastoral society, long range trade and slaving (see Fentress 2011; Gatto et al. 2019; Mattingly et al. 2017a). While it could be argued that the horse riders represent the pastoral 'military' muscle of these early Saharan civilisations (Scheele 2017), the interdependence of pastoralists and sedentary farmers was high - horses require a lot of water and do not endure being far from it for long periods, so the horse-breeding communities must have operated close to and within oases. The finds of quern stones and cereal grain at the described hillforts demonstrate that the people living there were either sedentarised or in close contact with an emerging oasis society a few kilometres away in the main Draa valley (and visible from the sites). As mentioned already, horses also require large amounts of cereals for their sustenance in desert environments (Dupuy 2017).

The horse and rider images could equally (or alternatively) represent a god or sacred ancestor. It is possible that the horse by itself had totemic value as a divine character or was a specific attribute of a Saharan divinity that could serve as a basis for communication between human communities and divine forces. The unusually focused imagery at the two sites discussed here - and the absence of similar imagery at other contemporary settlement sites is strongly suggestive of a special significance of the act of engraving at these locations, beyond simple personifications of individuals within society or concentrations of imagery at convenient stopping points along communication lines. Powerful ancestors could also be the object of worship, as demonstrated by the extraordinary funerary chapels from the broadly contemporary site of Jorf Torba in western Algeria, decorated with a great deal of engraved and painted imagery of horses, along with images of individual warriors and what appear to be family groups (Bokbot 2019; Camps 1984, 1995; Lihoreau 1993; Reygasse 1950). The context of the horse imagery (both riderless and with riders) in the Jorf Torba funerary chapels certainly suggests a sacred purpose. On an even larger scale, the late antique monumental tombs in Western Algeria known as the Djedar are also relevant here, featuring horse imagery on monuments that embodied reverence of ancestral power (Kadra 1983; Laporte 2005). Laporte (2005: 350-51) discusses two scenes of particular relevance for us: one with a mounted horseman following an ostrich with a dog, with two individuals behind perhaps making the orant gesture, the other showing a standing figure in the orant pose between a horse and a large feline. There is a symbolic language that unites the Djedar, Jorf Torba and the Tinzouline sites and these sites all seem to date to the centuries around the mid-1st millennium CE.

Comparison of the image assemblages from our two sites with Foum Chenna (TINo12) reveals many similarities but also some intriguing differences (Table 1, with Fig. 23). At Foum Chenna (see Fig. 3), there is a stronger martial component, with riders and standing figures much more commonly depicted armed with shield and sometimes with lance (Searight 2001: 129; cf. also Bravin $2020,7)$ and often shown in pursuit of hunted prey (10 scenes) or in combat with other armed individuals (4 occurrences). The martial figures at Foum Chenna constituted around 23 percent of all image components, 
compared to c.1o percent at TINoo1 and 5 percent at TINo15. The iconography at TINo15 still had a distinctly equid flavour accounting for more than 5 o percent of all figures. However, unlike TINoo1 and TINo12, the horse and riders (234) were outnumbered there by riderless horses (522) across the site. Although there are quite a few hunting scenes within the 'sacred area' at TINo15, it is tempting to relate the unusual abundance of riderless horses with a local concern for horse breeding, possibly evoking horse fertility or health. One image from TINo15 depicts a horse within an enclosure (Fig. 9e, RA 353) and another argument for stock raising comes from the array of enclosures on the lower slopes at TINool.

It is interesting to reflect on the locational differences between the two major concentrations of imagery (TINo15 and TINo12), one on the top of a prominent hill with exceptional views towards the Draa, the other at the liminal point were a narrow valley opened out into a wider plain. It is plausible to adduce that both locations already had special significance in the social landscape prior to the establishment of the settlements adjacent. From this perspective, despite the discernible different emphases evident in the iconography from the two concentrations, the pecked images concentrated along the main lane through the habitation area at TINoo1 and TINo15 appear more similar to each other in that they provide a distinctive echo of the major rock art station, marking out their proximity to a 'sacred' locus.

Another feature of the Tinzouline imagery that hints at a primary religious function is the artificial posture of many riders and other figures with arms in the so-called 'orant' pose (upper arms angled down, forearms raised up) - this is also a prominent feature of the Jorf Torba tombs and some similar funerary chapel tombs with paintings of people found by us in the Draa. One of the larger panels at TINo15 features two standing figures, depicted at larger scale within a field of horses and riders (Fig. 15b-c). They both appear to be holding items in their hands in an offering pose ('orant'). This suggests that something devotional or transactional was intended by such depictions.

While our attention is inevitably drawn to the best executed, largest and most coherent compositional scenes at TINo15, an equally striking aspect of the site is the fact that hundreds of individual horse and other animal engravings were seemingly added to certain rocks at different times and perhaps by multiple individuals with varying degrees of skill and effort. Over time, this created a palimpsest effect in the densest areas of engravings. This suggests that the execution of an engraving (regardless of artistic merit) was an important act, with profound social meaning for those that carried it out. The hilltop site at TINo15 was not a convenient resting place along a Saharan trail by a spring or a shady cliff face, but a brutally exposed hilltop accessed (if you did not live there) by a demanding climb up from the valley below. It seems evident that many different people made that trip over the years (some of course may have been inhabitants of the settlement, but others could have come from further afield). Whatever the precise significance of the carvings, it seems reasonable to infer that they relate to communication with a divine power: seeking fortune and protection, for instance, on a hunt or journey, or enhanced fertility for horse stock or better rainfall or for some other purpose over which a powerful divine force had influence.

At the start of the article, we underscored the need to look for evidence of rock art at more NAIA sites. That is not to say that we should expect to find it everywhere in fact, both in our work on the Libyan Garamantes and on the Gaetuli of the Draa, we have found the combination of settlement sites and rock art to be exceptional. Barnett (2019a: 259-62) notes that while an important cluster of rock art images related to the 1st millennium вСЕ Garamantian hillfort of Zinkekra, similar engravings were almost entirely absent from other early settlements in her surveyed zone of the al-Ajal (although they existed in the close surroundings). Similarly Garamantian burials were not generally associated with contemporaneous engraved imagery. However, a key point to note is that where this does occur - as at Zinkekra and the Tin sites - it relates to locations that had some special significance within society. There is other evidence to suggest that Zinkekra for instance, had particular sacred associations and that it was a pivotal place in Early Garamantian society (Barnett 2019a: 260-61; Mattingly 2010: 66-68, 75). In the Middle Draa survey, TINoo1 and TINo15 are thus far unique as settlement sites with significant associated rock art assemblages and this highlights their exceptional importance archaeologically. As work progresses on these sites we shall hopefully not only open a window on the social world of the western Gaetuli, but also build a bridge between rock art studies and the broader discipline of archaeology, to which the evocative iconography contributes such rich and suggestive documentation.

\section{Acknowledgements}

Funding for the 2015-2016 fieldwork of the MDP was primarily from the European Research Council grant for the Trans-SAHARA Project (Grant no: 269418), with support for the post-field research from an Arts and Humanities Research Council Grant for the OasCiv project ( $\mathrm{AH} /$ 
Too2409/1). The project remains indebted to Aomar Akerraz, Director of INSAP at the time of the original fieldwork and to our many supporters in the local area. Field recording of the rock art, including photography and fixing DGPS position for the images in 2015-2016 was primarily carried out by Youssef Bokbot, David Mattingly, Martin Sterry, Julia Nikolaus, Nick Ray, Nichole Sheldrick, and Rachael Sycamore. Nichole Sheldrick was responsible for final image interpretation and data tabulation and Martin Sterry for the GIS mapping and spatial analysis of the data. Geodrone Survey (Jonathan Adams, Joseph Bassett and Jason Hagon) carried out the drone surveys. The final writing of this article has been led by David Mattingly and Martin Sterry, but all the named authors have made important contributions to its authoring and editing. We are grateful to two anonymous referees for some helpful comments on a first draft of the article.

\section{References}

Abioui, M., M'Barki, L., Benssaou, M., Ezaidi, A. and El Kamali, N. 2018. Rock art conservation and geotourism: A practical example from Foum Chenna engravings site, Morocco. Geoconservation Research 2.1, 1-11.

Amara, I. 2003. Nouvelle approche de l'art rupestre de l'Atlas saharien: les figurations de la période tardive. New approach of rock art of Saharan Atlas: the latest figurations. L'anthropologie 107, 533-557.

Amblard, S. and Vernet, R. 1984. Des gravures rupestres intégrées à une structure d'habitat. L'exemple d'Akreijit. Journal des africanistes 54.1, 67-78.

Anderson, H. 2016. Chariots in Saharan rock art: an aesthetic and cognitive review. Journal of Social Archaeology 16.3, 286-3o6.

Barbaza, M. 2012. Les gravures rupestres libyco-berbères: d'une rive à l'autre du Sahara. In Fauvelle-Aymar Fr.X. (ed.) Palethnologie de l'Afrique, P@lethnologie 4, 169-193.

Barnett, T. 2019a. An Engraved Landscape. Rock Carvings in the Wadi al-Ajal, Libya. Volume 1: Synthesis. London, Society for Libyan Studies.

Barnett, T. 2019b. An Engraved Landscape. Rock Carvings in the Wadi al-Ajal, Libya. Volume 2: Gazetteer. London, Society for Libyan Studies.

Barnett, T. and Guagnin, M. 2014. Changing places: Rock art and Holocene landscapes in the Wadi al-Ajal, south-west Libya. Journal of African Archaeology 12(2), 165-182.

Bokbot, Y. 2019. Protohistoric and pre-Islamic funerary archaeology in the Moroccan Pre-Sahara. In Gatto et al. 2019a, 315-340.
Bradley, R. 200o. An Archaeology of Natural Places. London, Routledge.

Bravin, A. 2014. L'art rupestre de la phase des cavaliers au Maroc: les sites de Foum Chenna (Vallée du Draa) et du Jebel Rat (Haut Atlas): Analyse iconographique, thématique et proposition de chronologie. $\mathrm{PhD}$ thesis. Université Aix-Marseille.

Bravin, A. 2020. Les cavaliers dans l'art rupestre. Le cas du Maroc. TRACCE Online Rock Art Bulletin 46, 1-9.

Campbell, A., Coulson, D., Challis, S. and Keenan J. 2006. Some Mauritanian rock art sites. Sahara 17, 143-148.

Camps, G. 1974. Lâge du tombeau de Tin Hinan, ancêtre des Touareg du Hoggar. Zephyrus 25, 497-516.

Camps, G. 1984. Rex gentium Maurorum et Romanorum. Recherches sur les royaumes de Maurétanie des $\mathrm{VI}^{\mathrm{e}}$ et $\mathrm{VII}{ }^{\mathrm{e}}$ siècles. Antiquités africaines 20, 183-218.

Camps, G. 1995. Djorf Torba. Encyclopédie berbère 16 DjalutDougga. Aix-en-Provence, Edisud, 2477-2488.

Camps, G. and Gast, M. (eds). 1982. Les chars préhistoriques du Sahara. Aix en Provence, Institut de Recherches Méditerranéennes.

Capel, C. 2020. At the dawn of Sijilmasa: New historical focus on the process of emergence of a Saharan state and a caravan city. In Sterry and Mattingly 2020, 594-62O.

Daumas, E. 1968. The Horses of the Sahara (trans. S.M. Ohlendorf). Austin and London, University of Texas.

Desanges, J. 1962. Catalogue des tribus africaines de l'antiquité classique à l'ouest du Nil. Dakar, University of Dakar.

Di Lernia, S. and Zampetti, D. 2008. Le pitture rupestri dell'Acacus tra passato e futuro. Firenze, All'Insegna del Giglio.

Duckworth, C., Cuénod, A. and Mattingly, D.J. (eds). 2020. Mobile Technologies in the Ancient Sahara and Beyond. Trans-Saharan Archaeology Volume 4. Cambridge, Cambridge University Press and The Society for Libyan Studies.

Dupuy, C. 2017. Chars sahariens préhistoriques et araires africains actuels. I. L'alimentation des animaux de trait. Les Cahiers de l'AARS 19: 29-44.

Fentress, E. 2011. Slavers on chariots. In Dowler, A. and Galvin, E. (eds), Money, Trade and Trade-routes in Pre-Islamic North Africa, London, British Museum, 64-71.

Fentress, E. 2019. The archaeological and genetic correlates of Amazigh linguistics. In Gatto et al. 2019, 495-524.

Fothergill, B.T., Linseele, V. and Valenzuela Lamas, S. 2020. Movement and management of animals in the North and West of Africa 1000 BC to AD 1000. In Duckworth et al. 2020, 143-182.

Gatto, M.C., Mattingly, D.J., Ray, N. and Sterry, M. (eds). 2019. Burials, Migration and Identity in the Ancient Sahara and Beyond. Trans-Saharan Archaeology Volume 2. Cambridge, Cambridge University Press.

Gauthier, Y. and Gauthier, C. 2011. Des chars et des Tifinagh: étude aréale et corrélations. Les Cahiers de l'AARS 15, 91-118. 
Gauthier, Y. and Gauthier, C. 2015. Nouvelles figurations de chars sahariens: Technicité et positionment chronologique relativement au style de Tazina. Les Cahiers de l'AARS 18, $5^{-70 .}$

Gauthier, Y. and Gauthier, C. 2018. Petit manuel d'attelage: gravures et peintures de chars sahariens. Les Cahiers de l'AARS $20,37-88$.

Glory, A., Allain, C. and Reine, M. 1955. Les gravures rupestres

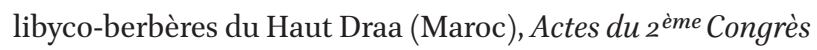
Panafricain de Préhistoire, Alger, 1952, 715-722.

Hamdoune, C. 2018. Ad fines Africae Romanae. Les mondes tribaux dans les provinces maurétaniennes. Bordeaux, Scripta Antiqua.

Holl, A.F.-C. 2002. Time, space and image making: Rock art from the Dhar Tichitt (Mauritania). African Archaeological Review 19.2, 75-108.

Kadra, F. 1983. Les Djeddars, monuments funéraires berbères de la région de Frenda. Alger, opU.

Laporte, J.-P. 2005. Les djeddars, monuments funéraires berbères de la région de Frenda et de Tiaret. In Briand-Ponsart, C. (ed.), Identités et cultures dans l'Algérie antique, Rouen, Presses Univ Rouen, 321-406.

Law, R. 1980. The Horse in West African History: The Role of the Horse in the Societies of Pre-Colonial West Africa. Oxford, Oxford University Press.

Lenssen-Erz, T. 1992. Coherence - a constituent of 'scenes' in rock art. Rock Art Research 9.2: 87-105.

Le Quellec, J.-L. 1993. Symbolisme et art rupestre au Sahara. Paris, Harmatten.

Le Quellec, J.-L. 2004. Rock Art in Africa: Mythology and Legend. Paris, Flammarion.

Le Quellec, J.-L. 2008. Du neuf avec de l'ancien: à propos des gravures et inscriptions du monument d'Abalessa. Sahara 19, $178-183$.

Lhote, H. 1982. Les chars rupestres sahariens. Des Syrtes au Niger, par le pays des Garamantes et des Atalantes. Toulouse, Ed. des Hespérides.

Lhote, H., Camps, G. and Souville, G. 1989. Art rupestre. Encyclopédie berbère fasc 6, Aix-en-Provence, Edisud, 918-939.

Lihoreau, M. 1993. Djorf Torba, nécropole saharienne antéislamique. Paris, Karthala.

Lutz, R. and Lutz, G. 1995. The Secret of the Desert. The Rock Art of the Messak Settafet and Messak Mellet, Libya. Insbruck, Golf Verlag.

MacEachern, S. 2001. Early horse remains from northern Cameroon. Antiquity 75(287), 62-67.

Mattingly, D.J. 2003. The Archaeology of Fazzan. Volume 1, Synthesis. London, Society for Libyan Studies.

Mattingly, D.J. 2007. The Archaeology of Fazzan. Volume 2, Site Gazetteer, Pottery and Other Survey Finds. London, Society for Libyan Studies.
Mattingly, D.J. 2010. The Archaeology of Fazzan. Volume 3, Excavations Carried out by C.M. Daniels. London, Society for Libyan Studies.

Mattingly, D.J. 2013. The Archaeology of Fazzan. Volume 4, Survey and Excavations at Old Jarma (Ancient Garama) carried out by C.M. Daniels (1962-69) and the Fazzan Project (1997-2001). London, Society for Libyan Studies.

Mattingly, D.J., Leitch, V., Duckworth, C.N., Cuénod, A., Sterry, M. and Cole, F. (eds). 2017a. Trade in the Ancient Sahara and Beyond. Trans-Saharan Archaeology Volume 1. Cambridge, Cambridge University Press.

Mattingly, D.J., Bokbot, Y., Sterry, M., Cuénod, A., Fenwick, C., Gatto, M., Ray, N., Rayne, L., Janin, K., Lamb, A., Mugnai, N. and Nikolaus, J. 2017b. Long-term history in a Moroccan oasis zone: The Middle Draa Project 2015. Journal of African Archaeology 15, 141-172.

Mattingly, D.J., Sterry, M., al-Haddad, M. and Bokbot, Y. 2018. Beyond the Garamantes: The early development of Saharan oases. In Purdue et al. 2018, 205-228.

Mattingly, D.J., Bokbot, Y. and Sterry, M. 2019. The Middle Draa Project (Morocco): Results from the survey and trial excavations 2015-18. Libyan Studies 50, 73-8o.

Mitchell, P. 2015. Horse Nations: The Worldwide Impact of the Horse on Indigenous Societies Post-1492. Oxford, Oxford University Press.

Mori, F. 1998. The Great Civilization of the Ancient Sahara. Rome, L'Erma di Bretscheider.

Moumane, A., Delorme, J., Ewague, A., al-Karkouri, J., Gaoudi, M., Ista, H., Moumane, M., Mouna, H., Oumouss, A., Lmejidi, A. and Zdaidat, N. 2019. Jbel Bani rock art: Newly-discovered shelters along mountain paths suggest a significant link between Central Sahara and North Africa (Zagora, Southern Morocco). Journal of African Archaeology 17, 1-17.

Muzzolini, A. 1990. Au sujet de la datation des chars au galop volant. Sahara 2, 115-118.

Pichler, W. 1999. The first Libyco-Berber inscriptions of the Anti-Atlas. Sahara 11, 146-147.

Pichler, W. 200oa. The Libyco-Berber inscriptions of Foum Chenna/Morocco. Sahara 12, 176-178.

Pichler, W. 20oob. Die Felsbilder von Foum Chenna/Oued Draa (Marokko): Ein Spiegel der nordsaharischen Berberkultur im 1. Jahrtausend B.C. Almogaren 31, 117-124.

Pichler, W. and Le Quellec, J.-L. 20o9. Considerations on the sign [hook] and the problem of its interpretation in Tifinagh inscriptions. Sahara 20, 203-210.

Pichler, W. and Rodrigue, A. 2001. Libyco-Berber inscriptions at Oued Meskaou/Morocco. Les Cahiers de l'AARS 6, 23-24.

Pichler, W. and Rodrigue, A. 2003. Some new Libyco-berber inscriptions in Southern Morocco. Cahiers de l'AARS 8, 23-24.

Pichler, W. and Rodrigue, A. 2011. The rock art site of Hadjart (Taouz, Morocco). Almogaren 42, 51-62. 
Purdue, L., Charbonnier, J. and Khalidi, L. (eds). 2018. Des refuges aux oasis: Vivre en milieu aride de la Préhistoire à aujourd'hui. XXXVIII ${ }^{e}$ rencontres internationales d'archéologie et d'histoire d'Antibes, Antibes, Éditions APDCA.

Reine, M. 1969. Les gravures pariétales libyco-berbères de la haute vallée du Draa. Antiquités africaines 3, 35-54.

Reygasse, M. 1950. Monuments funéraires préislamiques de l'Afrique du Nord. Paris, Arts et Métiers Graphiques.

Rodrigue, A. 1989. Nouvelles gravures rupestres dans la région de Zagora. Bul. Soc. Etudes et de Rech. Préh. Des Eyzies 38, 43-49.

Rodrigue, A. 2008. Les chars gravés du Jbel Aoufilal (Taouz, Maroc). Almogaren 39, 7-17.

Ruhlmann, A. 1939. Les recherches de préhistoire dans l'extrême Sud marocain. Pub. du Service des Antiquités du Maroc, fasc.5, 88-96.

Scheele, J. 2017. The need for nomads: Camel-herding, raiding and Saharan trade. In Mattingly et al. 2017a, 55-79.

Searight, S. 2001. The Prehistoric Rock Art of Morocco: A Study of its Extension, Environment and Meaning. Unpublished $\mathrm{PhD}$ thesis, Bournemouth University.

Simoneau, A. 1972a. Les prospections rupestres dans la région du Drâa (Extrême Sud marocain), Avril 1971-avril 1972. Almogaren 3, 15-33.

Simoneau, A. 1972b. Nouvelles recherches sur les gravures rupestres du Haut-Atlas et du Drâa. Bulletin d'archéologie marocaine 8, 15-36.

Simoneau, A. 1977. Catalogue des sites rupestres du sud Marocain. Rabat, Ministère des Affaires Culturelles.
Skounti, A., Zampetti, D., Oulmakki, N., Ponti, R., Bravin, A., Tajeddine, K. and Nami, M. 2012. Rock art and archaeology in Ifran-n-Taska (Eastern Jebel Bani, Morocco): First results of the Moroccan-Italian Research Project. In Huyge, D., Van Noten, F. and Swinne, D. (eds), The Signs of Which Times? Chronological and Palaeoenvironmental Issues in the Rock Art of Northern Africa, Royal Academy for Overseas Sciences, Brussels, 3-5 June, 2010, 109-136.

Sterry, M. and Mattingly, D.J. (eds). 2020. State Formation and Urbanisation in the Ancient Sahara and Beyond. Cambridge: Cambridge University Press.

Sterry, M., Mattingly, D.J. and Bokbot, Y. 2020. Pre-Islamic oasis settlements in the Western Sahara. In Sterry and Mattingly 2020, 239-276.

Trousset, P. 2012. Nomadisme (Saharien en Afrique du nord dans l'antiquité). Encyclopedie berbère fasc 34, Aix-en-Provence, Edisud, 5578-5589.

Webb, J.L.A. 1993. The horse and slave trade between Western Sahara and Senegambia.Journal of African History 34, 221-246.

Wolff, R. 1982. Contribution à l'étude des chars rupestres du sud Marocain. In Camps and Gast 1982, 139-151.

Zampetti, D., Skounti, A., Oulmakki, N., Ouhammou, A., Ponti, R., Bravin, A., Sammartino, M.P., Tajeddine, K., Nami, M. 2013. Art rupestre d'Ifran-Taska, Djebel Bani oriental Maroc. Résultats de prospection, d'analyse et de datation. Bulletin d'archéologie marocaine 23, 79-88. 